\title{
In search of the chains that hold Brazil back
}

\author{
Ricardo Hausmann \\ CID Working Paper No. 180 \\ September 2008
}

(C) Copyright 2008 Ricardo Hausmann and the President and Fellows of Harvard College

\section{Working Papers Center for International Development at Harvard University}




\title{
In search of the chains that hold Brazil back
}

\section{Ricardo Hausmann}

September 2008

\begin{abstract}
This paper performs a Growth Diagnostic for Brazil. It shows that many aspects of the Brazilian economy have been improving including the macro picture, educational progress and the external front. Moreover, Brazil has many productive possibilities and high-return investments. Yet growth is hampered because of a relatively old-fashioned problem that has been solved in many other countries in the region: creating a financially viable state that does not over-borrow, over-tax or under-invest. We show that domestic saving is the binding constraint on growth and that it has a fiscal cause. Although things are trending in the right direction, the challenge is to exploit the current good times to create the fiscal basis for a sustained growth acceleration.
\end{abstract}

Keywords: Growth diagnostics, Brazil

JEL Codes: O54 


\title{
In search of the chains that hold Brazil back
}

Ricardo Hausmann

\author{
Harvard Kennedy School \\ and \\ Center for International Development \\ Harvard University
}

August, 2008

\begin{abstract}
This paper performs a Growth Diagnostic for Brazil. It shows that many aspects of the Brazilian economy have been improving including the macro picture, educational progress and the external front. Moreover, Brazil has many productive possibilities and high-return investments. Yet growth is hampered because of a relatively old-fashioned problem that has been solved in many other countries in the region: creating a financially viable state that does not over-borrow, over-tax or under-invest. We show that domestic saving is the binding constraint on growth and that it has a fiscal cause. Although things are trending in the right direction, the challenge is to exploit the current good times to create the fiscal basis for a sustained growth acceleration.
\end{abstract}

Paper prepared for the Brazilian Center for Public Leadership. I would like to thank Luiz Felipe d'Avila for encouraging this research and to Bailey Klinger, Ugo Panizza and Rodrigo Wagner for useful comments. I would like to acknowledge excellent research assistance by Andrés Echeverry, Martín Hommes, Sandro Parodi and Dimitri Stoelinga. All errors are mine. 


\section{Happy days are here again}

Brazil's macroeconomic performance since 2004 has been remarkable. After courting financial meltdown during the electoral campaign of 2002 the country has been able to become investment grade. Five-year GDP per capita growth is higher now than any time in the last generation (Figure 1). Moreover, investment growth at about 16 percent has been expanding much faster than output suggesting that the sustainable rate of GDP is also going up.

While inflation is going up worldwide, due to the rise in food and energy prices, it has been particularly subdued in Brazil, averaging around 6 percent in mid-2008, better than Chile, Colombia, China, India and Singapore, not far from the US and Mexico and way better than Argentina, Egypt, Russia, Turkey, South Africa and Venezuela.

As opposed to previous growth accelerations such as those in the mid-1980s and 1990s, this time growth is not associated with an unsustainable domestic spending boom supported by deteriorating external and fiscal. On the contrary, the performance of the export sector has been quite remarkable in volume terms (Figure 2) and the improvement in the external and fiscal accounts look impressive (Figure 3). Net FDI inflows and reserve accumulation has been also very strong. The improvement in fiscal indicators is also remarkable. Debt to GDP ratios are coming down, reflecting improving primary and nominal balances, currency appreciation and an accelerating GDP (Figure 4). The currency mismatch in the public debt has been eliminated. Now, for the first time ever, a currency depreciation leads to an improvement instead of a deterioration of the debt indicators. Country risk indicators (Figure 5) have tended to converge with those of investment-grade Chile and Mexico and move away from the rest of the emerging market class. The country has been spared the financial turmoil that grips the US and Europe with banks still expanding their balance sheets at falling interest rate spreads. While the world is suffering a bout of angst, consumer confidence in Brazil is way up. Brazil looks posed to abandon its boom-bust cycles and enter a period of sustained growth and social progress. 


\subsection{Given the macro performance, the rate of growth looks surprisingly low}

But no all is so rosy. The level of growth per working age person since 2004 at 1 percent does not look impressive given the potential for recovery from the 2002-2003 recession and the performance elsewhere in the emerging market world. In fact, it looks quite dismal given the positive context. It is one of the lowest in Latin America in the 20042007 period (Figure 6). True, Argentina and Venezuela's growth was to a large extent based on a recovery from their very nasty recessions in the 1998-2003 period, but even if one looks at 1997-2007, Brazil's growth looks very poor (Figure 7).

More seriously, the low growth rate of Brazil is not the consequence of negative cyclical effects. On the contrary, according to the Central Bank current total GDP growth, running over 5 percent in the year to mid-2008 is above potential and needs to slow down to something closer to 4 percent for total GDP or 2 percent for GDP per working age person.

There are many indicators to suggest that current growth is above potential. First, over the course of the last 18 months, and coinciding with a concomitant up-tick in growth, imports have been rising at a very fast pace wiping out the current account surplus that was achieved in the previous three years (Figures 2 and 3). This indicates that demand is rising faster than supply. Secondly, there has been a very rapid appreciation of the real exchange rate (Figure 8), not only as reflected in a nominal appreciation of the multilateral exchange rate but also in a rate of inflation among non-tradables that is faster than among tradable goods. This is surprising because in most countries, the acceleration of inflation has been associated mostly with rising food and energy prices. However, in Brazil, tradable inflation (which includes food and energy) has been around 5.5 percent while non tradables inflation has been 6.5 percent (Meirelles, 2008).

So the sustainable rate of growth in Brazil at present is below 5 percent. This is surprisingly low, given that the working age population is rising almost at 2 percent per year. In addition, there has been a trend towards greater female labor force participation, 
meaning that the potential labor force should be rising even faster (Figure 9). Third, there has been a trend towards greater urbanization, which traditionally has implied a composition effect that raises productivity and growth (Figure 10). Fourth, there has been an important trend towards greater average schooling of the labor force. In fact, the rate of improvement in education over the past 15 years has been impressive (Figure 11).

Under these circumstances, a potential growth rate of some 4 percent for total GDP looks particularly modest in terms of growth per potential worker and is much lower than that achieved by Brazil in the 1960s and 1970s or that achieved elsewhere today in comparable countries. In this respect, it is interesting to look at the comparative rates of growth of per capita income over a 20 year period since 1960. While Brazil achieved its record growth in the 1960-1980 period (Figure 11), there are plenty of countries that have achieved higher rates of growth than Brazil's current 20-year per capita growth rate of just 1 percent or even than Brazil's 1960-1980 record at 4 percent.

Moreover, the growth rate of Brazil appears to be surprisingly low from the perspective of productive transformation. Hausmann, Hwang and Rodrik have developed a measure of export sophistication (EXPY) - based on the income per capita of countries with comparative advantage in each good - and shown that this measure is highly predictive of future growth: countries tend to converge to the income level of their competitors. Figure 13 shows that Brazil has a very sophisticated export package for its income level while Figure 14 shows that growth between 1992 and 2003 has been low relative to what would have been expected given initial sophistication.

Hausmann and Klinger (2007) have developed a measure of the ease with which countries can achieve structural transformation (open forest). They also show that this measure correlates well with growth and diversification. Again, here Brazil appears in a privileged position (Figure 15) but does not have the growth that would have been expected. 
So, the major puzzle is: why is the speed limit of the economy so low in Brazil? What are the binding constraints that may explain this slow growth?

\section{A growth diagnostic approach}

The growth diagnostic approach (Hausmann, Rodrik and Velasco, 2004) is based on the idea that there may be many reasons why an economy does not grow, but each reason, if valid, generates symptoms about its presence. These symptoms can become the basis of a differential diagnostic in which the analyst tries to differentiate among potential explanations for the low potential growth rate of the economy.

A typical medical researcher asks questions such as: does molecule $\mathrm{X}$ affect the level of variable $\mathrm{Y}$ in the average person of a certain population? $\mathrm{X}$ could be salt and $\mathrm{Y}$ could be blood pressure. X could be an analgesic and Y could be a headache. But in contrast to the medical researcher, the medical doctor asks the question: would $\mathrm{X}$ help this particular patient? The two questions are not totally unrelated, but they are quite distinct.

Similarly, an economic researcher asks the question: "does variable $\mathrm{X}$ affect the rate of growth of the average economy chosen at random from a certain population?" X could be the level of inflation, the average tariff rate, the level of spending in schools or the independence of the central bank. An economic advisor would ask the question: for this particular country, at this particular time, what should the government do to achieve sustained and shared growth? Again, the two questions are not completely independent, but neither are they the same. Not by a long shot.

Much of the empirical research on growth has been addressed at the question of what variables are causally associated with growth in the average country. A workhorse of this research agenda has been the Barro-style (1991) cross-country growth regression. There have been literally millions of regressions run with all sorts of explanatory variables, including geographic, institutional, demographic and policy variables of many sorts ${ }^{1}$.

\footnotetext{
${ }^{1}$ For a recent application of this approach to the case of Brazil see Adrogué, Cerisola and Gelos (2006).
} 
It seemed obvious to take one of those estimated regressions and use it to design a growth strategy for a country. Suppose the equation had two variables that are hard to change such as geographic latitude and the average age of the population. So, you disregard them and focus on those that seem more amenable to be influenced by policy. You might find credit to the private sector as a share of GDP and secondary school enrollment as two variables that appear to be statistically and economically significant and potentially amenable to policy change. Why not base a growth strategy on an education plus finance mix of policies?

There are two reasons that may give you pause. The first is that governments do not decide either how much credit the private sector will get from private banks or how many kids stick around until they finish high school. The second reason is that while in the average country it may be true that a higher level of credit to the private sector may be associated with higher growth, you have no certainty that your country is an average country in this particularly respect. Similarly, while aspirin may relieve pain for the average patient, you may think twice before giving it to your particular patient if he suffers from stomach ulcers.

So, should you expect your country to be average in terms of its reaction to credit easing or educational improvements? One quick test might be to see whether your country's low private credit ratio is related to low supply or low demand? You can tell one from the other by looking at the interest rate. If supply (demand) was limited, you would expect to see a high (low) interest rate. If education was an important limitation on growth you would expect to see a high return to schooling, as estimated, for example, through a Mincer regression.

In other words, you would not start from the assumption that if a variable is associated with growth in the average country, that it would be associated with growth in your particular country at the particular point in time in which you happen to be working. This 
is just like realizing that an aspirin is unlikely to make an ulcer patient feel any better even if many other patients do appreciate its effects.

This is the idea behind growth diagnostics. As a good doctor, you can know much more about your patient than what you know about the average man in the street. You do not want to suppress the information you have about your patient when you interpret the evidence coming from people you do not know. In other words, just because that information was not available for all the other patients in the regression, you should not disregard it when thinking about your patient.

Anna Karenina starts with the famous line: "Happy families are all alike; every unhappy family is unhappy in its own way." Paraphrasing Tolstoy: each developing country may be held back by very different things. The point of the growth diagnostic approach is to find out what these are.

Another important distinction between the growth diagnostic approach and the standard analysis emanating from Barro-style growth regressions is the idea that many of the determinants of growth are complements rather than substitutes. In the typical Barro regression, variables enter additively and separately on the right hand side of the equation. This means that poor performance in one area can always be compensated with over-performance in another area. Moreover, the impact of any policy on growth is independent of the level of the other variables ${ }^{2}$. This idea is best illustrated by looking at the structure of the two barrels in Figure $15^{3}$. The left hand barrel has the wood slabs in a horizontal position, while the right hand side barrel has them vertically. Clearly, the volume in the first barrel depends on the sum of the width of all slabs. The volume in the second barrel is determined by the length of the shortest slab. Two implications of the second barrel is that the impact of a change in a slab on the volume of the barrel depends

\footnotetext{
${ }^{2}$ In principle, one can put interaction terms, which would cause the impact of one variable to depend on the level of another. However, there are so many potential interaction terms that the degrees of freedom of the estimation collapses very rapidly. See Rodriguez (2007).

${ }^{3}$ The broken barrel was proposed by Justus von Liebig, the "father of the fertilizer industry" to explain the fixed proportions of nutrients that go into plant development. It was suggested to me by Rodrigo Wagner. See Hausmann, Klinger and Wagner (2008).
} 
on whether it is the binding constraint or not. If not, the impact is zero. If it is the binding constraint, the impact will depend on the distance between the shortest slab and the next shortest slab. In other words, the impact of a relaxation of the binding constraint, if large enough, will depend on the distance to the next binding constraint. This will turn out to be an important idea for the discussion that will follow.

The world is probably not as extreme as these two images suggest. Things are neither perfect substitutes nor perfect complements, but awareness of the complementarities and their implications is important, given how much policy strategies have been based on the assumption of substitutability.

It is tempting to think that in a poor country, everything is binding because everything is in poor shape. But it is unwarranted to think that all dimensions are equally binding. Yes, infrastructure is lousy, banks are not Swiss (although Swiss banks are no longer what they used to be) and schools leave a lot to be desired. However, education may be lousy but other things may be so much worse that high-skilled individuals are either leaving the country or driving taxis. The banking system may be small, but banks may be full of liquidity and desperate to find sound customers to lend money to at very sensible interest rates. Why there are so few takers may be the question to ask.

So, if all possible constraints are not equally binding, which ones might be binding more? Which one, if relaxed, might allow for the biggest bang for the effort? This becomes the central question.

How should one proceed to look for potential binding constraints? One way to organize the search is to go down a decision tree as in Hausmann, Rodrik and Velasco (2005). The particular decision tree they propose is based on a general growth model and starts from the notion that in a growth path, the rate of growth of the economy depends on the difference between the expected private return on investment and the cost of funds. Said differently, a country's growth may be low either because the expected returns to 
investment are low or because the cost of finance is high. This creates the first bifurcation in the decision tree (Figure 16).

Suppose that it is because the cost of finance is high. This can be due to the fact that there are insufficient sources of domestic savings coupled with problematic access to foreign savings or because there are problems the process of intermediation of the available savings.

Alternatively, suppose the problem is low private returns. This may be due to the fact that social returns are low or alternatively that they are high but not appropriable. And so on. The problem is how to know in which direction to move down the decision tree.

Here is where some tricks of the trade become really useful. First, if something is a binding constraint on growth, you should expect it to have a high actual or shadow price. If education is binding, the returns to those few lucky people that got a good education should be very high. If instead, the highly educated are leaving the country, something else must be binding even harder ${ }^{4}$.

Second, movements on the presumptive binding constraint should show up in movements of the aggregate growth rate. For example, if the hypothesis is that availability of finance is the binding constraint, you would expect changes in the observed market interest rates to show themselves up in the rates of growth or investment. But if one finds that growth and investment fell precisely at the same time that interest rates were falling and banks were full of liquidity, it would be hard to argue that lack of loanable funds was the problem.

Third, if something is really holding a society back, members of the society must be finding ways around it. If poor provision of property rights is the binding constraint, then

\footnotetext{
${ }^{4}$ If there are strong complementarities between two or more inputs and all are missing the returns to each will be low even though they collectively constitute the binding constraint. This is a possible hypothesis in some cases and should be checked using other tricks of the trade. I doubt that it is a relevant consideration for Brazil at this time.
} 
people would flock around those with political power and offer them shares in any new endeavor in exchange for protection. If poor financial intermediation is the binding constraint then those with profitable activities would become conglomerates that re-invest their profits in all sorts of activities.

Fourth, if you do not know why there are so few animals in the Sahara, it helps to note that the few animals you do find tend to be camels and not hippos. You would expect the camel to thrive in areas where water is scarce. You cannot go too wrong by inferring that the few things that survive in the Sahara are those that are least intensive in that which is missing: water. So, it is instructive to reflect upon what underpins the performance of the most successful parts of an economy: what are they least intensive in?

Fifth, it has become common practice in economics to blame credibility and expectations for the way things turn out in life. If a country is not growing, it is easy to argue that people do not invest because they do not believe that the future will be as good as the present. Since you cannot know what people think about the future, this appears to be, at first sight, an explanation that is plausible but hard to falsify. However, the experienced analyst would realize that if the argument is based on the idea that investors are scared by the possibility that something bad might happen in the future, it is important to check that profits today are reasonably high So, you would expect current earnings to be fine, but price / earnings ratio to be low: this would signal that today's earnings are not expected to last.

Finally, a constant cannot explain a variable. China's Confucian history and cultural tradition cannot be used simultaneously to explain why growth there has been so high since 1978 and so low from 1500 to 1978. The difference between Latin America's current low savings rate relative to East Asia cannot be explained by long standing cultural differences because the savings rate in Latin America in the 1960s were substantially higher than those in East Asia. 
Once the analyst has stumbled into a possibly binding constraint, it is useful to try to posit a syndrome, that is, an overall explanation or story that can account for why that particular constraint binds. This syndrome should explain the observed symptoms but should also have some other testable implications. The good analyst would check for these in order to convince himself that he has a robustly tested explanation for what is wrong with the country he is working on.

In terms of standards of evidence growth diagnostics resembles more the case of a civil suit than a criminal case. In the former, the decision criterion is "the preponderance of the evidence". In the latter, it is "beyond reasonable doubt". A policymaker cannot avoid making decisions and she will have to do so with the best available information and analysis, even if she would have wished to have more certainty than what can be provided. Economic analysis in the real world seldom provides enough information to quench all doubts. Cogent arguments may exist for an alternative story and it may be hard to tell stories apart. The role of the responsible analyst is neither to hide the doubts so as to create a wrong sense of infallibility nor to go into a nihilist attitude and avoid decisions. Instead, she should state the story she thinks is most plausible, describe the alternative stories that may account for the known facts and try to think through the strategies that could tell them apart. In addition, she could think of policy interventions that are expected to be appropriate for each scenario and ideally find a strategy that may work under all the possible stories.

The approach ends up being very Bayesian in flavor. You are looking for symptoms or signals that may orient you. You look at all prices and quantities you can get your hands on. To interpret the information, it is useful to remember the Bayesian equation. You start from certain prior beliefs of what the problem is. Then you find a symptom. You will update your beliefs about what is the right story depending on the ratio of the conditional probability that you would observe the signal if the story is right relative to the unconditional probability that you observe the signal. 
Let us take an example. Suppose the question is whether a particular air passenger is a terrorist. Your test is whether he is carrying a bomb. You would not expect a typical passenger to be carrying a bomb, but you assign a very high probability for a terrorist to be carrying bombs. So, Bayes' formula says that you should update your beliefs according to the ratio of the probability that a terrorist carries a bomb relative to the unconditional probability that any random person is carrying a bomb. Since your priors are such that you don't expect a normal passenger to be carrying a bomb but you would expect a terrorist to be carrying one, then finding a person with a bomb significantly changes your view as to whether he is a terrorist or not. By contrast, many terrorists have beards, but so do many non-terrorists. So, finding a person with a beard does not change your priors by as much as finding him with a bomb because the difference in the probabilities along the hypothesis is much smaller.

Unfortunately, in real life it is difficult to find single symptoms that pin down a diagnostic unequivocally. So you must rely on all the signals you can and try to make the most of it. Suppose you suspect that insufficient aggregate savings is the constraint to growth in a particular country. For this to be true, lending interest rates should be high, indicating that society is willing to pay a high price for more of the missing factor. But interest rates can be high for many reasons. For it to be a constraint in aggregate savings, the deposit interest rates or the rates paid by the government on its debt should also be high. Otherwise, the problem might be instead bad financial intermediation. But if aggregate savings are low, why can an investor not get his funds from the international market? Why does the country not borrow more from abroad to complement its meager domestic savings? The answer may be that the country as a whole already did borrow too much and that it has reached a credit ceiling. But then one would like to confirm this by showing that either the current account deficit or the accumulated debt are high and that country risk is particularly high. Moreover one would want to show that movements in this constraint get reflected in the level of domestic investment and growth.

In addition, economic analysis favors stories that are compatible with some kind of methodological individualism. The outcomes we observe must be some kind of 
equilibrium where individual agents cannot easily change things by just altering their individual behavior.

I find it useful to start a growth diagnostic with a good description of the growth process that includes not just the long view but also the fluctuations, as these may be indicative of movements in the binding constraint. Then one should move down a decision tree as proposed in Hausmann, Rodrik and Velasco (2005) or some other version constructed ad hoc for the issue in question. After one has located the country in the decision tree, it is important to formulate a syndrome: a story that explains what causes that particular constraint to be binding. This story generates an additional set of testable implications that should be checked with the facts.

This is the approach we will follow in the subsequent sections. We start with a brief description of the long run performance of growth in Brazil. Then we move on to the analysis of the decision tree. This will lead us to the view that the binding constraint on growth is insufficient aggregate savings. We will posit a syndrome: an over-extended state. We will further analyze additional testable implications of that syndrome. We will also ask the question: what other constraints might become binding if the savings constraint is relaxed. We end with a set of policy implications emanating from this analysis.

\section{Applying the growth diagnostic approach to Brazil}

Here it is useful to establish some stylized facts about Brazil that may be serve to make a diagnostic. Figure 17 shows the GDP per capita of Brazil as a fraction of the US GDP per capita. Part a looks at the very long run - since 1500 - while part b looks at the postWWII period. The first fact is that Brazil fell behind the US in the XVIII and XIX century. Growth in per capita income during the first half of the XXth century equaled that of the US on average, but it substantially exceeded that of the US in the 1945-1980 period when the relative income moved from about 15 percent of the US level to 30 percent. However, since 1980 relative income has fallen back to some 20 percent of the 
US level. Hence, an important question is what happened in the 1980s that caused a long term change in growth dynamics.

\subsection{The first level of the decision tree: is it low returns or high cost of finance?}

Let us now apply the decision tree to Brazil. Is the problem caused by low returns to investment or by high cost of finance? To ascertain this question it is important to note that real interest rates in Brazil are unusually high. In fact, using average real lending rates for 141 countries from the Economist Intelligence Unit, Brazil has the highest lending rates in the world ${ }^{5}$ (Figure 18). Now, given the lending rate, one would expect to find a very low investment rate. However, as figure 19 shows, on average between 2005 and 2007 there were plenty of countries with a similar investment rate but with an interest rate that was a small fraction of the Brazilian rate. If the investment ratio was similar but the interest rate was much higher this implies that the demand for investment function, which economic theory says should be equal to the marginal efficiency of investment, is much higher in Brazil than elsewhere, as illustrated in figure 20. To get a sense of the effect, just imagine what would be the investment rate in Brazil if the country faced Chilean interest rates.

Moreover, as argued above, if something is a binding constraint, one would expect that movements in it would have important effects. In this respect, it is interesting to note how real interest rates and investment co-move in Brazil. As shown in Figure 21, the investment rate in Brazil has been very sensitive to movements in the lending rate, as would be expected if it was a relevant constraint.

It may be argued that the lending rate from commercial banks in Brazil is not reflective of the effective rate paid by investors for their loans because there are several sources of below-market lenders of which BNDES is the most important. According to this argument, investment is not constrained by the high interest rates because at the margin

\footnotetext{
${ }^{5}$ A similar result is obtained for a much smaller set of countries using the Global Development Indicators of the World Bank.
} 
few investors face it. This argument cannot be right for several reasons. First, on a purely theoretical level, while investors may borrow from BNDES, they have an incentive to invest any extra resources they can get in the instrument that yields the highest possible risk adjusted return. Suppose that investors had access to the SELIC rate. They would borrow as much as possible at the subsidized rate and invest in machinery and equipment until their risk adjusted returns equaled the SELIC and the balance would be invested at the SELIC. They would not invest in their own firms unless they would expect to beat the SELIC. BNDES would need a huge police force to prevent this from happening, since money is fungible. True, the SELIC rate is significantly below the lending rate of banks, but it is a very high real interest rate nonetheless.

Second, BNDES is just not big enough. The gross disbursements of BNDES represented 25.7 percent of gross fixed capital formation in 2007. Moreover, much of gross disbursements represent refinancing of maturing loans. The net increase in long term loans, which would fund a net increase in assets, represents just 3.9 percent of gross fixed capital formation in 2007. It is hard to argue that at the margin investments are being financed by BNDES except in some selected sectors and programs.

Another argument is that some firms have access to international loans at much lower interest rates. This may well be true, but these firms would be wise to take those loans and invest in SELIC-indexed instruments unless the expected real return of capital in their firms was higher. Moreover, if all firms had such access we would not see a large and rising domestic credit market at the high real interest rates we do observe.

Hence, the bulk of investment is done by firms that at the margin require an after-tax return equal either to the market lending rate or to the interest rates at which they can place their savings. I conclude that the marginal efficiency of investment in Brazil is very high, probably one of the highest in the world. This means that we are clearly on the right hand side of the decision tree in Figure 16. The price of the constraint is high, as reflected in the interest rate. Movements of the interest rate reflect themselves in changes in 
investment and growth. Agents in the economy try to overcome the constraint through mechanisms such as BNDES and the like.

The fact that we are on the right hand side of the decision tree means that items on the left hand side are not the binding constraint. In particular, appropriability of returns is not a binding constraint. For example, according to the World Bank's Investment Climate Assessment Survey, firms in Brazil complain more than all 67 countries in the sample, except Benin, about the tax rates they have to pay (Figure 22). The same result obtains with regards to the costs associated with the tax administration system. Does this mean that the level of taxation is the binding constraint?

According to our analysis the answer is no: the level of taxation is not a binding constraint. In spite of the level of taxation, there is more demand for investment than loanable funds and as a consequence the real interest rate is sky-high. If the tax rate was lower, firms might use the freed cash flow to expand investment. But this would also have the effect of raising the demand for investment even more, and the interest rates would have to go up in order to keep the balance in the market for loanable funds. The point is that the returns to investment in Brazil are so high that even in spite of the discouraging impact of high taxes, investment demand would exceed available savings at the interest rates observed in most other countries. If the tax rate was the binding constraint one would expect to see a low demand for investment and hence a low interest rate. This, however, does not mean that the issue of taxation is not part of the overall story as we will discuss below.

A similar argument can be used with regards either to inadequate infrastructure or education. As we will see, public investment in infrastructure is dismally low and the returns to education are among the highest in the world. Is this not evidence that these are binding constraints? Well, no. Infrastructure and human capital are complements of private physical capital. If they were more amply supplied they would increase the demand for investment, raising the interest rate even more. The puzzle about Brazil is that in spite of inadequate infrastructure and education, investment demand has to be 
curtailed through an interest rate so high that would cause a major economic collapse in almost any other country.

\subsection{The second level of the decision tree: is it insufficient savings or poor intermediation?}

So, now that we have established that the cost of finance is the key problem in Brazil, the next question is to ascertain why this is so. Is it because savings are limited or because financial intermediation is highly inefficient? If the problem is financial intermediation, deposit rates would be relatively low, indicating that society is unwilling to remunerate savings very generously because they are not in short supply, and bank spreads would be high because intermediation is inefficient. By contrast, if the problem is lack of savings, the deposit rate and the rate paid by the government on its debt would be high. What is the situation in Brazil?

As Figure 23 shows, the average real deposit rate for the period 2005-2007 in Brazil was 9.1 percent (7.9 percent for 2007), the third highest - after Turkey and The Gambia - in a sample of 145 countries, where the median real deposit rate was zero. According to the latest fiscal data, the implicit interest rate paid by the government in its total net debt during the period May 2007- May 2008 was 15.5 percent. This implies a real interest rate of about 10 percent since inflation has been around 5 percent in the reference period. This is a very high cost of debt, especially in such a propitious period, indicating the tightness of the savings constraint.

Having said this, the spreads between lending and deposit rates are also huge. In fact, they are the highest in the EIU sample (Figure 24). To make sense of these results it is useful to write down a simple model of the relationship between deposit and lending rates in a competitive banking system. Assume that bank balance sheets are composed of loans (L) and reserves (R) on the asset side and deposit (D) and capital (K) on the liability side:

$$
L+R=D+K
$$


Reserves, either for liquidity demand reasons or because of mandated regulatory requirements must be a fraction $\varepsilon$ of deposits. For capital adequacy reasons, $\mathrm{K}$ must be a fraction $\kappa$ of loans.

$$
\begin{aligned}
& R=\varepsilon D \\
& K=\kappa L
\end{aligned}
$$

Let the lending and deposit rates be respectively $r_{L}$ and $r_{D}$ and the spread $s$ be just the difference: $s=r_{L}-r_{D}$

Let us assume that operating costs are a proportion $\mathrm{c}$ of the deposit base. Under perfect competition, economic profits would be driven down to zero. We assume for simplicity that capital requires the same rate of return as the lending rate and that reserve requirements are not remunerated. We therefore have that:

$$
r_{L} L-r_{D} D-r_{L} K-c D=0
$$

Substituting and solving for the spread as a function of the lending rate or the deposit rate we obtain:

$$
\begin{aligned}
& r_{L}(1-(\varepsilon+c))=r_{D} \\
& s=(\varepsilon+c) r_{L}=\frac{\varepsilon+c}{(1-(\varepsilon+c))} r_{D}
\end{aligned}
$$

So, the size of the spread is proportional to either the lending or the deposit rate, even in a perfectly competitive market. The cause of the spread is the fact that a portion of the assets are not usable for lending and are unremunerated and that operating costs are proportional to the asset or liability base. Hence, they act as a tax on financial intermediation.

To bring this simple model to the data we graph the spread against the lending rate for Brazil (Figure 25). The graph and regression show an almost perfect correlation between the two variables with an implied value of $\varepsilon$ of 0.63 . Note that the intercept in the 
regression is estimated at 3.5, a small fraction of the average spread in the period, suggesting that much of the spread is related to the level of the interest rate ${ }^{6}$.

How can we explain this? Brazil has one of the highest reserve requirement ratios. According to Carvalho and Azevedo (2008) Brazilian reserve requirement ratios on transaction accounts in 2004 were set at 53 percent and were by far the largest in the sample of countries considered in that paper. 0.53 is not too far from our estimate at 0.63 , especially considering that our model includes operating costs as part of the estimated coefficient. Operating expenses in Brazil reached 5 percent of assets in 2004, a number that is very high - about 5 times larger than in Hong Kong, Singapore and China but lower than in Nigeria, Venezuela, Ecuador, Ukraine, Colombia, Russia and Peru, but higher than the median of 3 percent for a sample of 31 countries (Economist Intelligence Unit).

The point is that the high spread in Brazil can be associated with the high level of interest rates and the high reserve requirement ratios, rather than inefficient financial intermediation. If the interest rates were to decline so would the spread, as has actually happened in the last 10 years where the spread declined from 58.4 percent in 1998 to 28.8 in 2007. I conclude that the spread is endogenous to the level of the interest rate and is not in itself the cause of the high generalized level of interest rates, but its consequence. It is also impacted by the high reserve requirement ratio, a theme we will return to later on.

Some have argued that there is evidence of oligopolistic behavior by Brazilian banks (Belaisch, 2003) questioning our assumption that profits are zero. But the paper rejects the assumption of monopolistic behavior by banks and finds no evidence of oligopolistic behavior by foreign banks and these have had a rising share of the Brazilian market. Moreover the estimated effect is small relative to the size of the spreads. Moreover, just the shear number of banks and of alternative financial institutions is such that it could not

\footnotetext{
${ }^{6}$ A more complex model could include a higher return to capital than the lending rate and costs that are not proportional to assets. These assumptions would be more appropriate but would complicate the model without changing the main message.
} 
explain why spreads are higher than in many other markets with much more concentrated structures.

In some countries, high interest rates may reflect yet unrealized expectations of inflation or depreciation. However, this is clearly not the case in Brazil during the recent past as there are good market estimates of inflation expectations and these have been subdued. Moreover, the market has seen a rapid rise in international reserves and a reduction in country risk. Therefore, we are left with the hypothesis that the problem in Brazil is an inadequate supply of savings, not a particularly inefficient financial intermediation, although there is some of that which will become part of the story we will elaborate later on.

Now, what is required for a story based on the idea that there is insufficient aggregate saving? Obviously, one part of the answer must be that domestic savings are low relative to investment demand. But domestic savings can be complemented with foreign savings. If the country is small relative to the global economy and if access to foreign savings was frictionless, then the domestic interest rate would be determined by the international rate and foreign savings would fill the gap between domestic savings and investment at the international rate. Clearly, Brazil has had a very unstable access to international savings. As recently as 2002-2003 the country had to borrow heavily from the International Monetary Fund (IMF) to shore up its foreign liquidity. Since then, its access to foreign borrowing has improved dramatically. At the same time, the improvement in export revenues - caused both by price improvements and a positive supply response - has lead to a significant increase in domestic savings. The improvement in access to both domestic and external savings has lead to rising investment and an acceleration of the rate of growth, as would be expected if the binding constraint is relaxed. When it tightened in 2002-2003 we saw a jump in domestic interest rates and a reduction in growth and investment.

There are limits to the amount that foreign savings can contribute fund domestic investment. First, clearly is the fact that as the foreign debt accumulates, concerns over 
either ability or willingness to pay causes the cost of foreign borrowing to go up or be shut down completely, as happened as recently as 2002-2003. But a second limitation comes from the fact that foreign savings can fund the increase in demand for all goods, but can only directly improve the supply of tradable goods, since in the end, it funds imports. This means that it increases the relative supply of tradables causing their relative price to fall, i.e. it causes the real exchange rate to appreciate. This will affect the relative composition of output and employment.

It is interesting to note that the non-tradable sector tends to be the skill intensive sector, where we define the tradable sector as agriculture, mining and manufacturing. The greater human capital intensity of the non-tradable sector is the case for a sample of developing countries (including Brazil) and the US, whether one looks at the average years of schooling of those employed in each sector (Figure 26), or at the proportion of employment with college education (Figure 27). This is not caused by the low skill intensity in agriculture. If we restrict the comparison between manufacturing and nontradables we still find that non-tradables are more skill intensive (Figure 28).

This means that as the reliance on foreign savings is increased, the relative size of the non-tradables sector expands and the severity of the skills constraint increases, causing the skill premium to rise. It is important to note that Brazil already has a very high return to schooling, whether one looks at the Mincerian returns to an additional year of schooling or to the college wage premium (Figures 29 and 30). Hence, reliance on foreign savings would exacerbate the skills constraint and cause even greater inequality. In short, as the reliance on foreign savings increases, the relative profitability of the tradable sector declines because relative prices move against it, as skilled workers are bid up in price by the expansion of the non-tradable sector.

In addition, changes in the relative tightness of the savings constraint reflect themselves in a volatile real exchange rate. Figure 31 shows the average volatility of the real exchange rate in the decade to 2007 and the log of GDP per capita. In spite of relatively moderate inflation in this period, Brazil shows a very high real exchange rate volatility 
suggesting that changes in the savings constraint may have been important and carried significant relative price implications.

Finally, as we said above, movements in the binding constraint should be reflected in the growth rate. The recent relaxation of the savings constraint has been accompanied by a rise in the growth rate, as would be expected.

In sum, Brazil is a country with a somewhat below normal investment rate but that happens in a context of record real interest rates. In fact, in order to prevent demand from exceeding supply and causing inflation, the Central Bank of Brazil (BCB) needs to set interest rates at levels that would drive any other economy into a deep recession. The country has relied on foreign borrowing for significant stretches of its history and limitations in that access have had important implications for growth, as happened in the 1980s and in 2002-2003. One can only imagine what would be the demand for investment in Brazil if the economy faced the kind of interest rates that are present in most other countries. The question is therefore: what syndrome may explain this phenomenon?

\subsection{The syndrome: an over-extended crowding-out state}

We will now posit a syndrome that may account for the high level of interest rates in Brazil and may explain other aspects of the economy as well. The syndrome is that of a state that is overburdened by obligations in the form of a large set of entitlements and other commitments. To achieve its commitments it has used all available means: high taxes, low public investment and a large fiscal deficit. This problem can in principle lead to different kinds of binding constraints. Too high a tax rate may discourage investment leading to low investment demand. Too low a public investment effort may cause bottlenecks leading also to low private investment demand. Alternatively, too high a fiscal deficit may lead to crowding out in the financial markets causing a high interest rate. Moreover, if the tax rate is high and public savings are negative then the private sector is left with a small share of after-tax revenues on which to base the whole national 
savings effort, further augmenting the tightness of the crowding-out effect. Which of these stories is plausible given the evidence?

First, public consumption as a share of GDP doubled during the 1980s (Figure 32) from around 10 to 20 percent of GDP. In response to this major shift in spending, general government revenues as a share of GDP responded with delay from less than 20 percent of GDP to over 40 percent in the current decade (Figure 33). This level of taxation is among the highest in the developing world. It is by far the highest in Latin America and only comparable to former communist countries such as Belarus, Croatia, Bosnia \& Herzegovina, Bulgaria and the Czech Republic or to countries whose governments rely on large natural rents or grants such as Burundi, Eritrea, Botswana, Angola and Equatorial Guinea (Figure 34).

In spite of this very high level of taxation, public investment is the lowest in a large sample of developing countries (Figure 35). In fact, it has averaged less than 2 percent of GDP, a figure smaller than the nominal deficit indicating that the government has been running negative public savings (Figure 36). Two elements weigh very heavily in the government budget: pensions and the interest on the public debt. Pensions clearly transfer resources to individuals with a very low propensity to save. Together with the increase in government consumption they create a heavily over-extended situation.

\section{Policy implications}

In a first best world, all distortions can be eliminated simultaneously and we live happily ever after. However, in many situations important trade-offs exist between lowering one distortion and aggravating others. Therefore, it is crucial to get a sense of the 'bindingness' of different constraints or distortions in order chart a course.

A first best solution to Brazil's growth problem would simultaneously lower the level of public consumption and transfers, increase investment in infrastructure and human capital and lower taxes, while reducing the overall deficit to create space for private investment. 
This implies clearly contradictory changes that are bound to be impossible to approve, coordinate and execute. Reductions in taxes and increases in investment don't go well with reductions in deficits.

A second best approach would take account of the difficulties involved and the appropriate sequence of events. A first challenge would seem to be the need to create an environment in which private investment can increase to exploit the many opportunities that seem to be present, as reflected in the fact that so much borrowing is taking place at exorbitant interest rates. At present, the Central Bank keeps the SELIC rate high because otherwise aggregate demand would exceed aggregate supply (or alternatively, investment would exceed savings) causing inflation to accelerate. Simply relying on external savings would generate the wrong pattern of investment and employment as it would appreciate the real exchange rate and skew resources to the skill-intensive non-tradable sector, where skill premia are already very high.

\subsection{Increase domestic savings}

Hence, as argued also in Bacha (2008), increasing domestic savings seems key. It would allow a greater level of domestic investment without relying excessively on external savings that may prove unsustainable and that would appreciate further the real exchange rate, bias growth towards non-tradables and accentuate the skills constraint.

A first line of attack is obviously public savings. At present, they are negative and gradually approaching zero. Public investment has been dismally low, but in spite of this, has been greater than the nominal deficit as discussed above (Figure 36). However, as a first priority, reducing the nominal deficit seems to be more important than increasing public investment, as there are very high returns to private investments that are being rationed out through high interest rates.

This does not mean that there are no public investments whose return is higher than the market interest rate. The portfolio of investment projects must have a whole distribution 
of expected returns and some may be truly astronomical. As we will discuss below, a look at the conditions in the infrastructure sector suggests that the privatization of telecoms and energy has resulted in an improved supply of these two activities. However, the transportation sector shows much weaker indicators, expressing the low levels of investment in this area.

Given the already very high rate of taxation in Brazil it seems reasonable to suggest that the increase in public savings should come out of a reduction in the share of current expenditures in GDP. In a growing economy, adjustments can be done by slowing down the rate of growth of spending rather than through actual cuts. However, there are some missed opportunities for improving the fiscal accounts that should be considered.

Historically, to protect investment from the extreme and volatile level of real interest rates the BNDES has been charged with providing much cheaper financing to selected activities. The long-term lending rates of BNDES are set as a mark-up on the Tasa de Juros de Longo Prazo or TJLP, which is set by the National Monetary Council as a weighted average of the forward looking inflation target for the next 12 months plus an estimate of a forward looking risk premium (BNDES, 2008). It is a rate paid on the forced savings of the FAT the Workers Welfare Fund. Whatever the calculation, it is set well below the SELIC rate with the differential that has fluctuated between 500 and 850 basis points since 2004 (Banco Central do Brasil, Table 3-01i). The lending rates charged by the BNDES are calculated as a mark-up on the TJLP and are thus thousands of basis points below the lending rate charged by commercial banks, which have to pay among other things a very large implicit tax through the reserve requirements, as discussed above.

The system on which the BNDES operates can be conceived as an implicit tax on workers who are forced to save at below market rates in order to fund investment at preferential rates. This is clearly a distortion in the economy but it can be justified on second-best grounds as a way of protecting high return investments from the main distortion in the economy, which is the government's crowding out effect on all 
investment. But the costs fall on workers while the benefits are going to borrowers who are appropriating the differential between the lending rate of BNDES and the rate at which they arbitrage their investments. It has distortionary effects on the labor market, encouraging informality and on the banking system. It would be ideal to have a strategy whereby, as the main distortion of the system is reduced through the improvement of the government's fiscal situation and the decline in real interest rates, these BNDES-related distortions are also lowered.

But instead of keeping the BNDES lending rates constant as the SELIC has been falling, the BNDES rates have been reducing rates almost pari passu preventing a reduction in the distortion. This is a missed opportunity. Assuming that workers will be implicitly taxed by the FAT anyway (a point to which I return below), the opportunity cost of the BNDES resources is clearly the marginal cost of public debt. Any difference between that interest rate and the risk-adjusted lending rate must be considered an implicit subsidy to investors.

The reason the SELIC rate is high is because the $\mathrm{BCB}$ tries to limit aggregate demand. The higher the interest rate set by the BNDES on its loans, the lower the SELIC the BCB would need to set in order to achieve its inflation target. Hence, a strategy of not responding to SELIC easing with reductions in the BNDES lending rate would accelerate the decline in the SELIC and the improvement in the nominal deficit.

This result emerges through several channels. First, the SELIC is set endogenously considering the conditions of aggregate demand in the economy. The more expansionary the BNDES, the more contractionary the BCB needs to be. Second, the cost of the public debt is highly affected by the SELIC and not by the TJLP or the lending rate of BNDES. Third, the higher the interest rate charged by BNDES and the higher the proportion of its assets invested at market rates, the better would be its financial results, thus helping public savings. In other words, BNDES operations are a form of tax expenditure where resources that could be used to retire public debt are used instead to provide belowmarket loans to the private sector. This reduces overall savings, which has the general- 
equilibrium effect of reducing private investment even if it is done with the idea of increasing it $^{7}$.

Also, a strategy to reduce the differential between the BNDES lending rates and the private market rates would allow the banking system to get increasingly involved in longterm lending, an activity that was stunted during the high inflation period and that has been taken over by the public sector through its subsidized lending. A strategy that would achieve "normal" interest rates in Brazil should also permit a "normal" long term credit market.

Clearly, whether the BNDES should benefit from the higher lending rates or should it be instead the workers through a higher interest rate on their FAT savings (or even a reduction in the contributions to the FAT) is a distributive question best left to the participants in the domestic political game. The point is that it makes little sense for the $\mathrm{BCB}$ to be putting its feet on the breaks while the BNDES is putting its feet on the accelerator. If BNDES would take its feet off, the $\mathrm{BCB}$ could ease up, the interest rates would come down and the fiscal dynamics would improve.

Beyond public savings, there is private savings. Part of the problem of low savings in Brazil is related to the fact that the high marginal tax rates affect corporations and individuals that have high propensities to save while much of the transfers accrue to pensioners and other recipients with low propensity to save ${ }^{8}$.

In addition, the pay-as-you-go social security system reduces incentives to save by the current young generation. Reforms in this area could further increase the savings behavior of the public. It may also be interesting to explore tax schemes that create incentives to save.

\footnotetext{
${ }^{7}$ In fact, in its December 2006 Inflation Report the BCB argued that the reduction in the TJLP prevented the reductions in the SELIC from achieving a greater improvement in the position of the Public Sector Net Debt.

${ }^{8}$ While these features are common to many countries, they are particularly extreme in Brazil because of the extreme values of tax revenues and pension payments and public savings, as a share of GDP.
} 
One form of implicit taxation that has deleterious effects on savings behavior is the presence of high reserve requirements on banks. Carvalho and Azevedo (2008) estimate the implicit revenue received by the Central Bank for the below market rates paid on reserve requirements at 500 million reais per month or some 1 percent of federal revenues. Clearly, this is not a large amount in terms of its impact in debt dynamics, but it does represent a major distortion in terms of raising the spread between deposit and lending rates and hence lowering the efficiency of financial intermediation and the incentives to save. A strategy to reduce implicit taxation on financial intermediation would be a priority given our view of savings as a binding constraint.

\subsection{Address public sector supply bottlenecks}

Clearly, a higher rate of private investment would create a more rapid increase in potential supply and allow the $\mathrm{BCB}$ a more rapid expansion of demand without fearing inflation. However, as the economy expands it will be putting additional pressure on the complementary factors that are under the responsibility of the government. Infrastructure and education are two such areas. We have already noted the fact that the supply of education seems to be rising rapidly and the returns to education have been on a downward path in recent times, suggesting that trends in this area are positive.

The situation looks more difficult on the infrastructure side. The public investment in infrastructure has decreased in relative terms to GDP, particularly for transport, a sector which has shown signals of decay. The period since 1980 witnessed a sustained decline in public infrastructure spending (Figure 32). The most dramatic decline occurred in the 80 's, when overall investments in infrastructure plunged from 5.2 percent of GDP in 1981-85 to 2.4 percent of GDP 1996-2000 (World Bank, 2007a). Between 1995 and 2003 it fell from 2.5 percent of GDP to just over 1 percent (Figure 37).

According to the World Bank (2007b), the main reasons for the decline of public infrastructure investments include the deterioration of the institutional framework for public investments and the crowding out effect of public investments by federal current 
expenditures. In addition, private financing of infrastructure has not compensated for the fall of public expenditures, yielding a negative impact in net infrastructure investments. Private investment has been concentrated in telecoms and energy (electricity and natural gas) sectors which together represent 86 percent of all private investment in infrastructure (Figure 38). It has been deterred in other areas by the volatility of concession returns and poor cost recovery records (mostly dues to poor enforcement of tariffs and devaluation). According to the World Competitiveness Report, Brazil lags behind selected sample of LAC in terms of road and port infrastructure. Air transport also lags behind but less dramatically, although recent accidents suggest otherwise.

True, since 2002 investment has been rising albeit from dismally low levels. Moreover, it is occurring in a context of negative public savings and still very high real interest rates, so any increase would have to be bounded by even higher increases in public savings.

\section{Concluding remarks}

Brazil is in a unique situation in Latin America. While most countries are in search of the products through which they can integrate their people to the global economy, Brazil is innovating in a set of high tech activities in agriculture, energy, aircraft, mining products, design, machinery and autos, among many others. The country has many possibilities through which it can sustain growth for many years. In addition, health and education are improving and the democratic system has been made to work. Since 1990, life expectancy has increased by 5 years and the mean years of schooling of the labor force by 4 years. These are major achievements. And yet, Brazil has been unable to generate a significant growth acceleration.

The analysis provided in this paper suggests that this is because of a relatively oldfashioned problem that has been solved in many other countries in the region: creating a financially viable state that does not over-borrow, over-tax or under-invest. In fact, several countries in the region have problems growing in spite of the fact that they have 
adequately addressed these fiscal issues and have been able to achieve low interest rates and adequate infrastructure: just look at Chile.

Brazil fares better than almost all other countries in the region in terms of the possibilities for productive transformation. But these remain stunted by an environment that makes investment and growth difficult. True, things are trending in the right direction. Real interest rates have come down considerably as has the net public debt and the nominal deficit. The challenge is to exploit the current good times to create the fiscal basis for a sustained growth acceleration. While the political costs of creating a viable state should not to be under-estimated, neither should the economic, social and political benefits this course of action would generate, given the relatively quick growth pay-off in terms of growth. 


\section{References}

Adrogué, Ricardo, Martín Cerisola and Gastón Gelos (2006) "Brazil's Long-Term Growth Performance - Trying to Explain the Puzzle", IMF Working Paper 06/282 (December).

Bacha, Edmar L. (2008) Por Que o Juro É Tao Alto E O Crescimento Tao Baixo?" http://iepecdg.com/DISK\%201/Arquivos/ArtigosBacha/080512Palestracbpf.pdf

Belaisch, Agnés (2003) “Do Brazilian Banks Compete?” IMF Working Paper WP/03/113.

Blyde, Juan, Armando Castelar Pinheiro, Christian Daude and Eduardo Fernández-Arias (2008) "What is stopping growth in Brazil?", mimeo: Inter-American Development Bank

BNDES (2008) “Long Term Interest Rate”, July 17. http://www.bndes.gov.br/english/bndes/tjlping.pdf

de Carvalo, Fabia A and Cyntia Azevedo "The Incidence of Reserve Requirements in Brazil: Do Stockholders Share the Burden?" Central Bank of Brazil, Working Paper Series No. 160, February 2008.

Hausmann, Ricardo, Jason Hwang and Dani Rodrik (2007) "What you export matters" Journal of Economic Growth 12.1 (March 2007): 1-25.

Hausmann, Ricardo and Bailey Klinger (2007) "The Product Space and the Evolution of Comparative Advantage", Center for International Development, WP No. 146, April.

Hausmann, Ricardo, Bailey Klinger and Rodrigo Wagner (2008) "Handbook on Growth Diagnostic", mimeo Center for International Development.

World Bank (2007) "Brazil Improving fiscal circumstances for growth”; March.

World Bank (2007) "Brazil: How to Revitalize Infrastructure Investments in Brazil Public Policies for Better Private Participation" 
Figure 1. Total GDP per capita growth and 5-year moving average (centered)

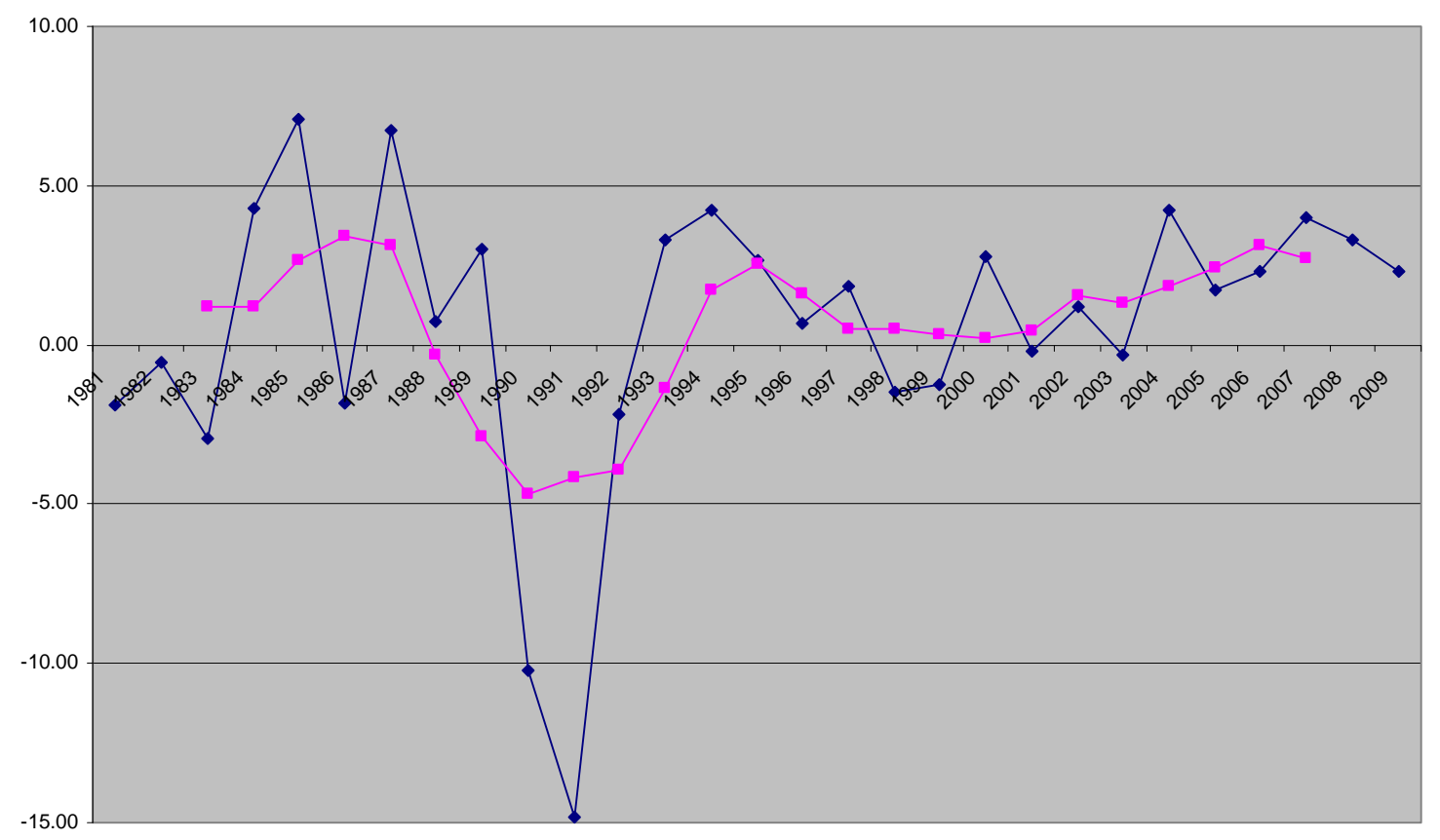

Source: Economist Intelligence Unit. 2008-2009 are projections

Figure 2. Real exports and imports of goods and services (constant local currency units)

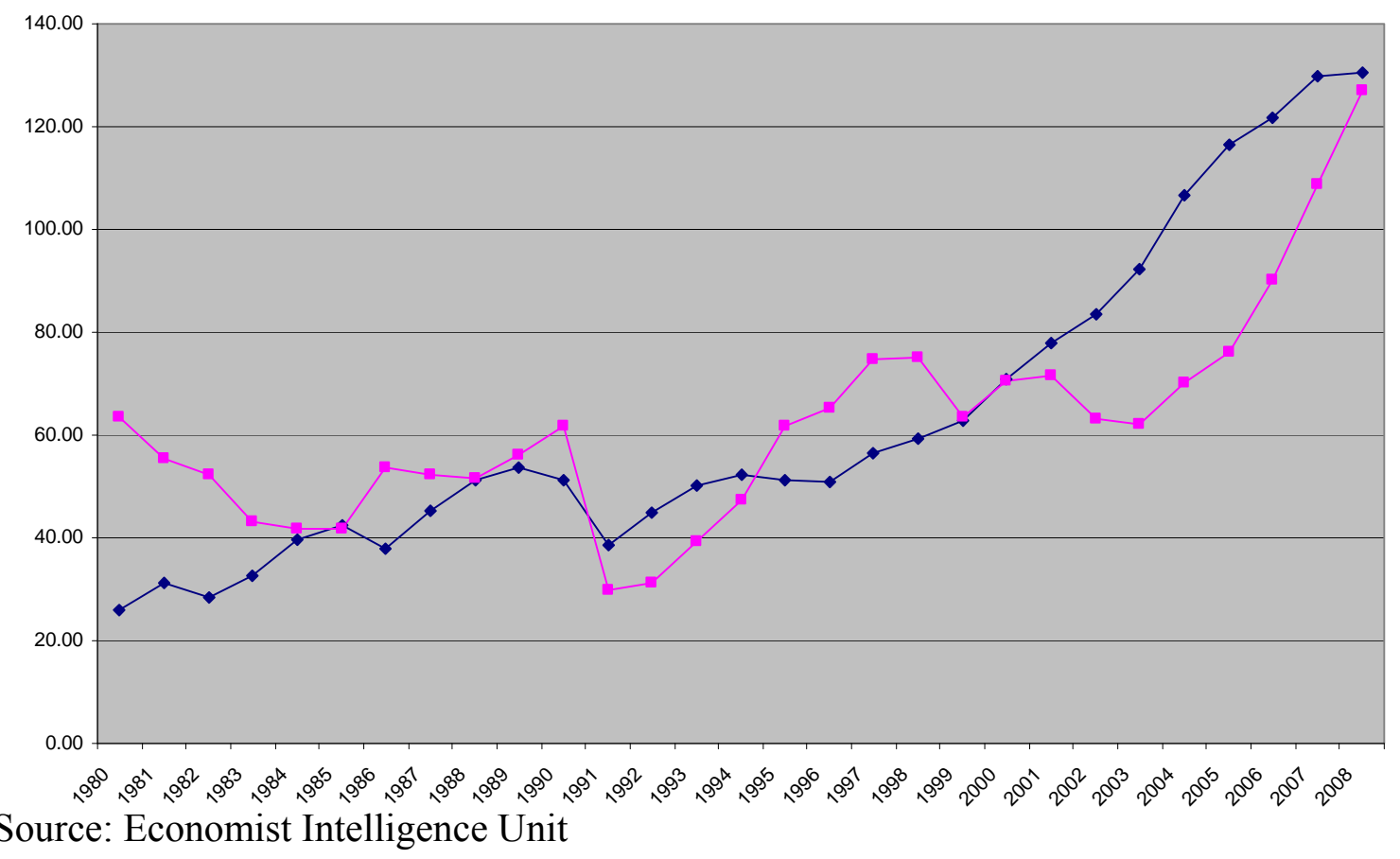

Source: Economist Intelligence Unit 
Figure 3. Current account and general government balance as a share of GDP

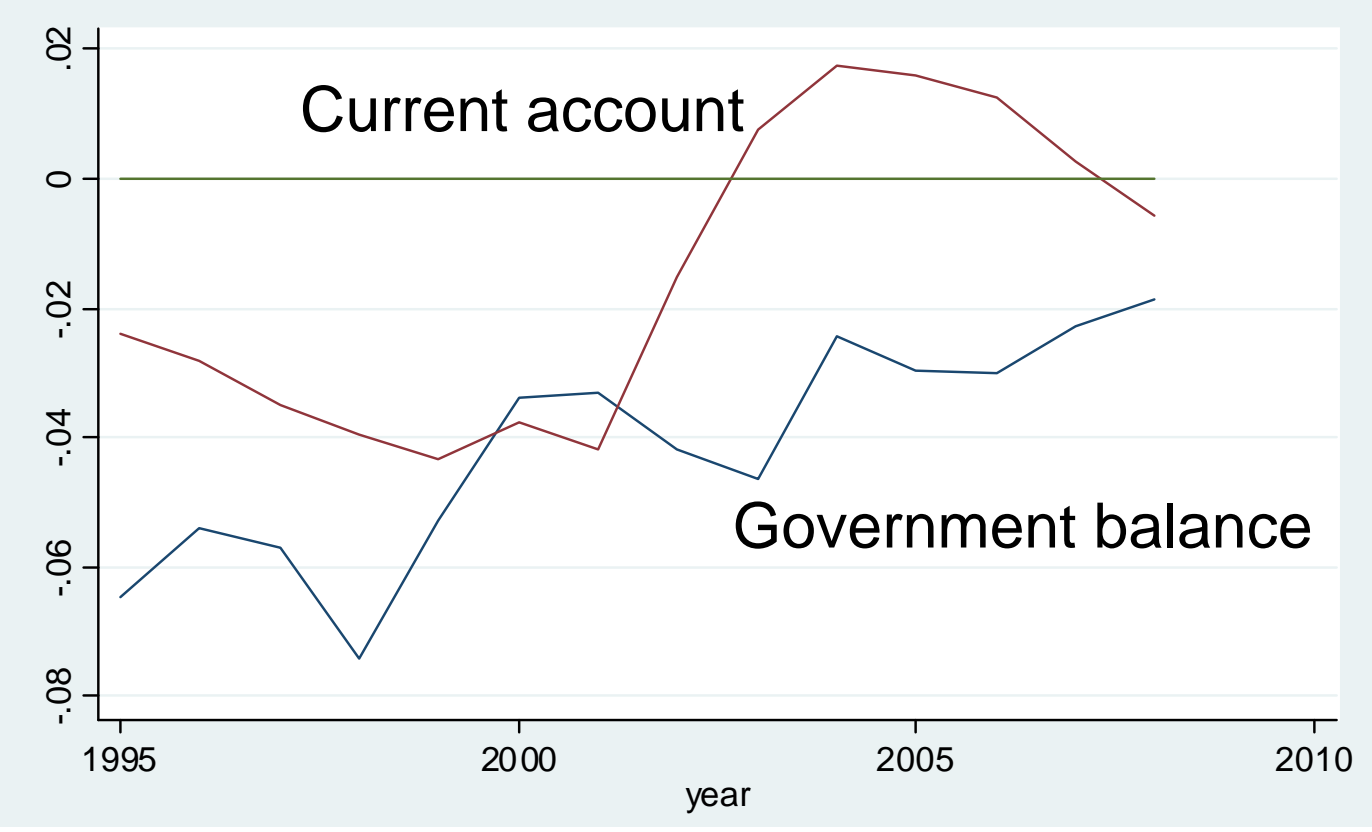

Source: International Monetary Fund

Figure 4. Net General Government Debt as a share of GDP

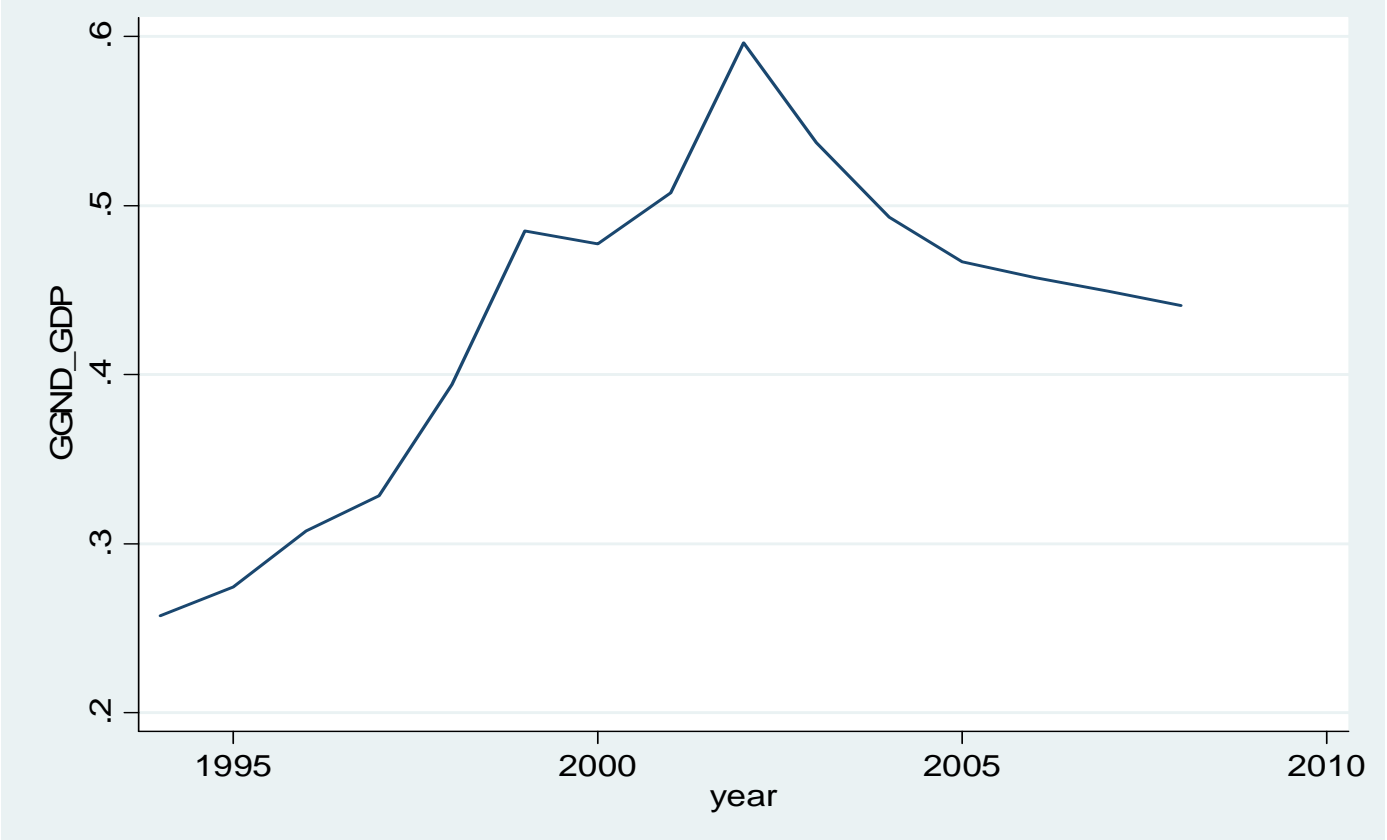

Source: International Monetary Fund 
Figure 5. Country risk indicators

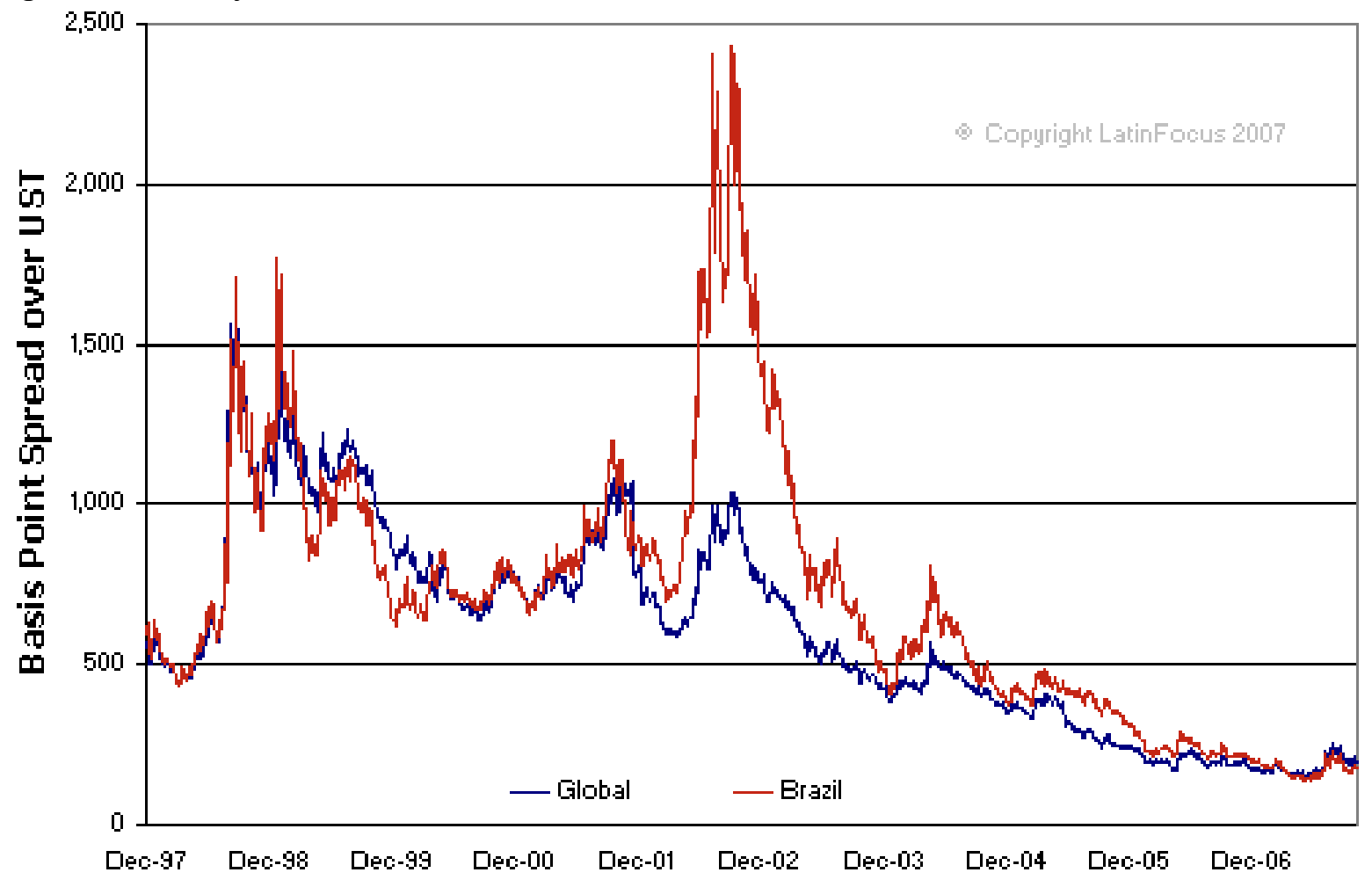

Figure 6. Rate of growth of GDP per working age person 2004-2007

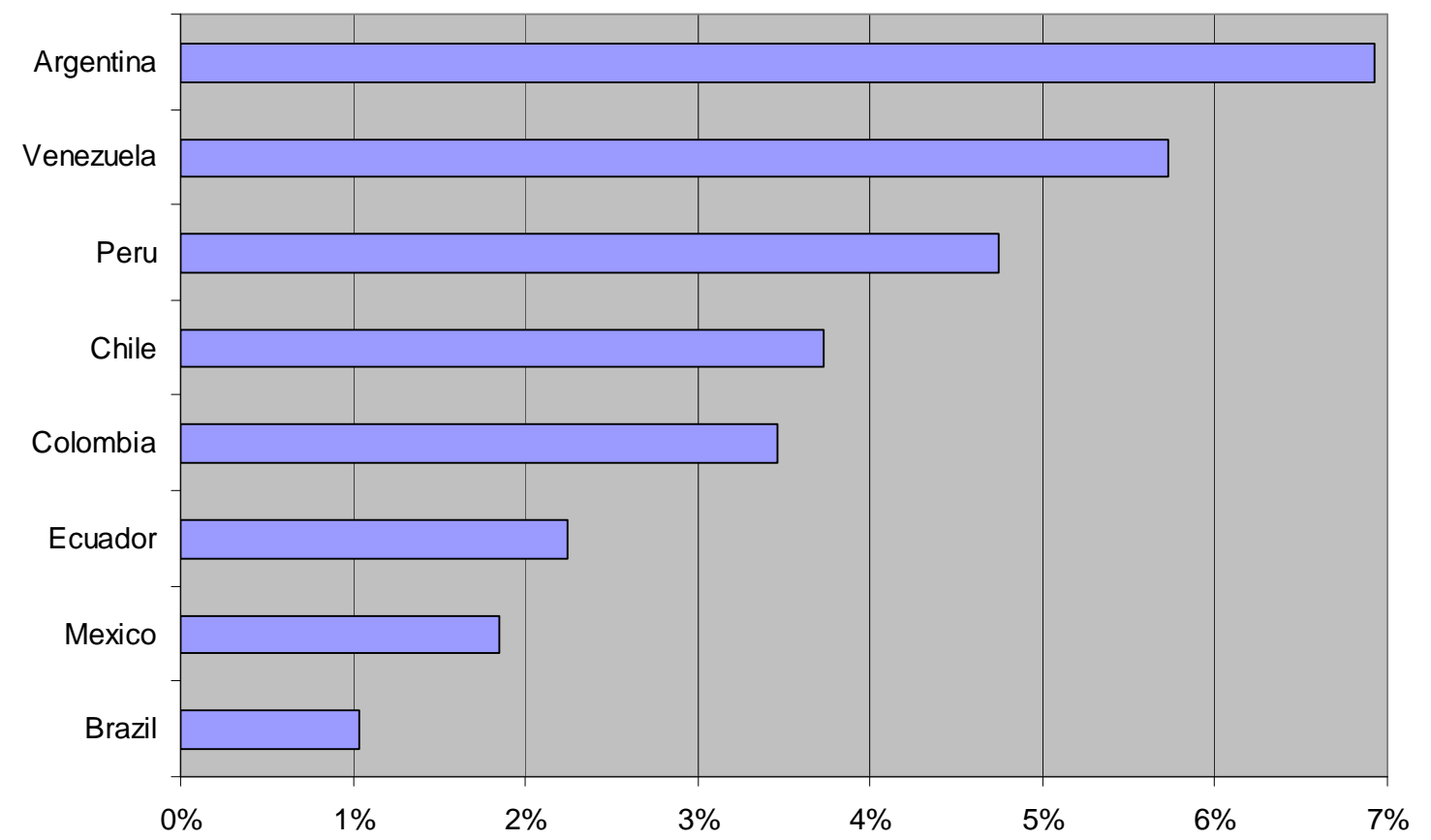

Source: Economist Intelligence Unit 
Figure 7. Growth in GDP per working age person \{Dates ??\}

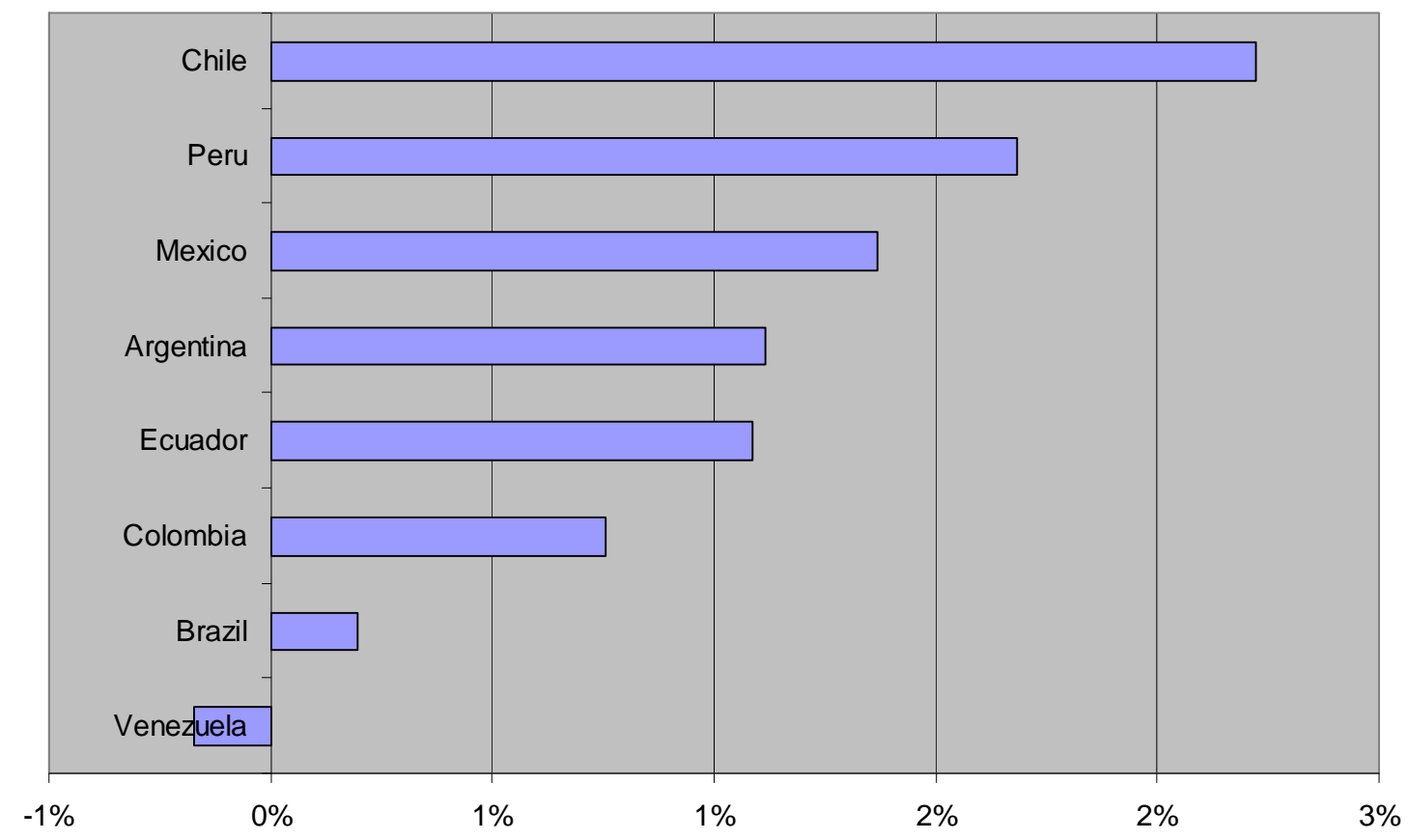

Source: Economist Intelligence Unit

Figure 8. Real effective exchange rate

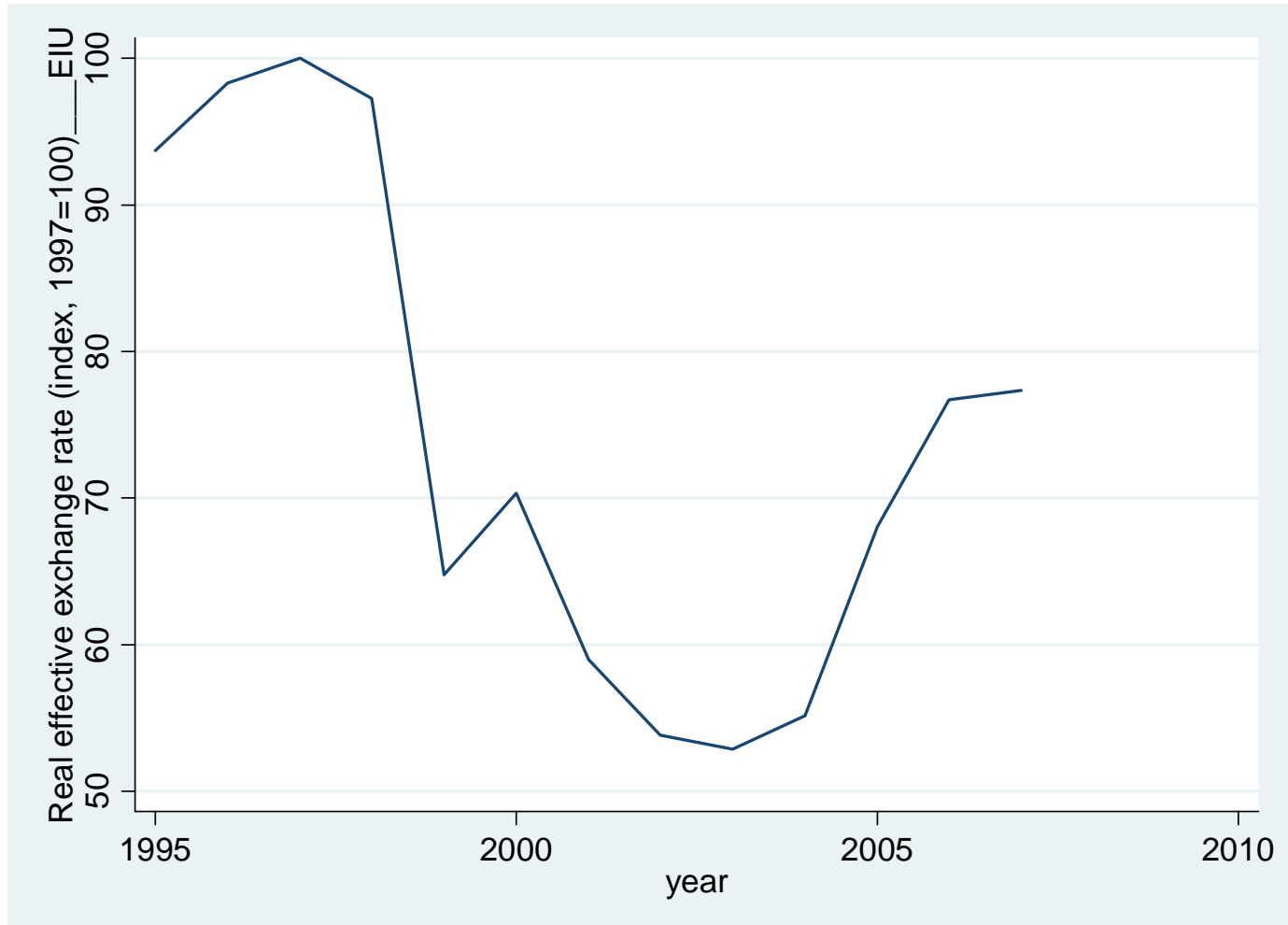

Source: Economist Intelligence Unit 
Figure 9. Female labor force as \% of total labor force

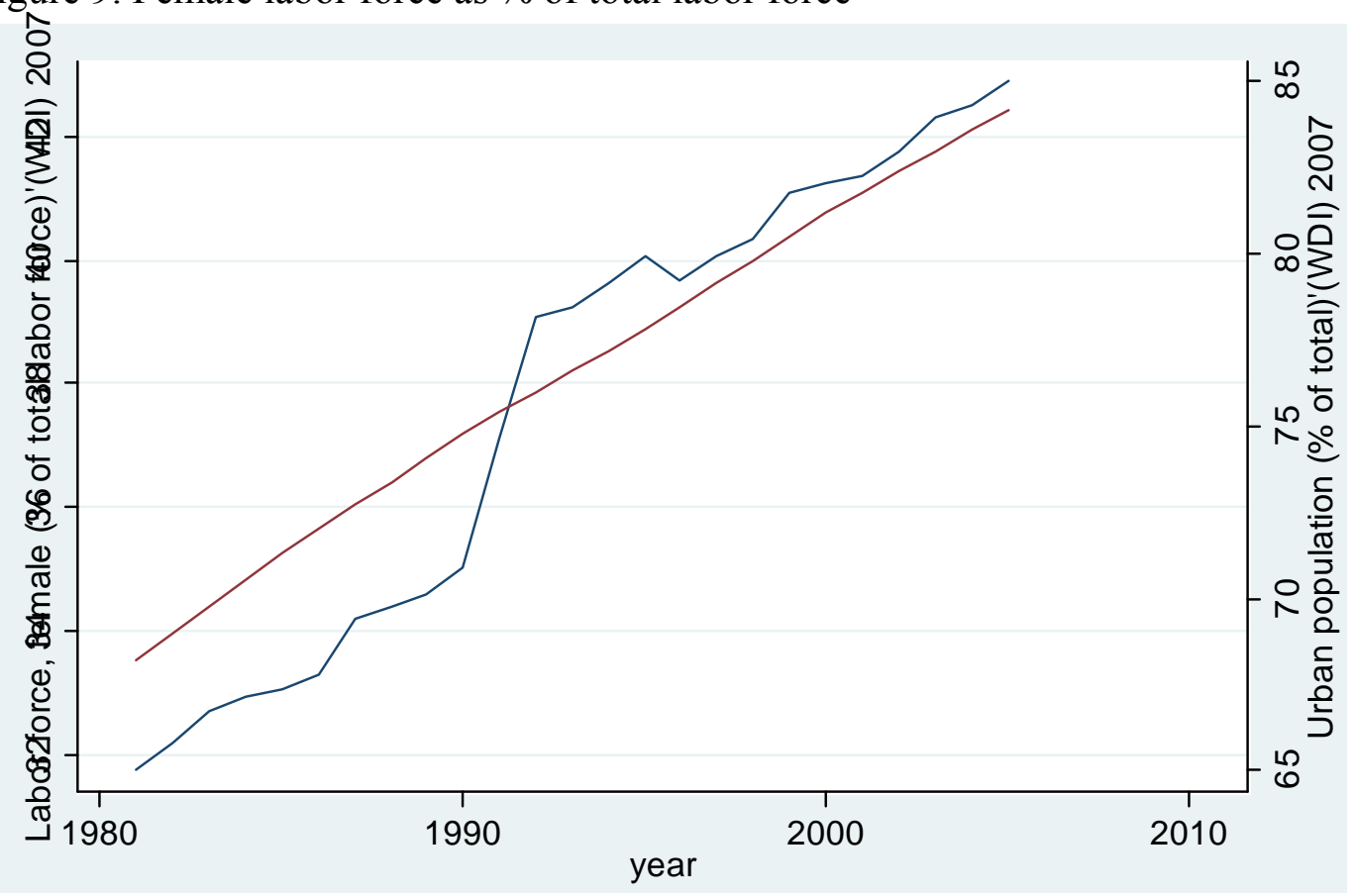

Source World Development Indicators

Figure 10. Mean years of schooling of the labor force and secondary school enrollment

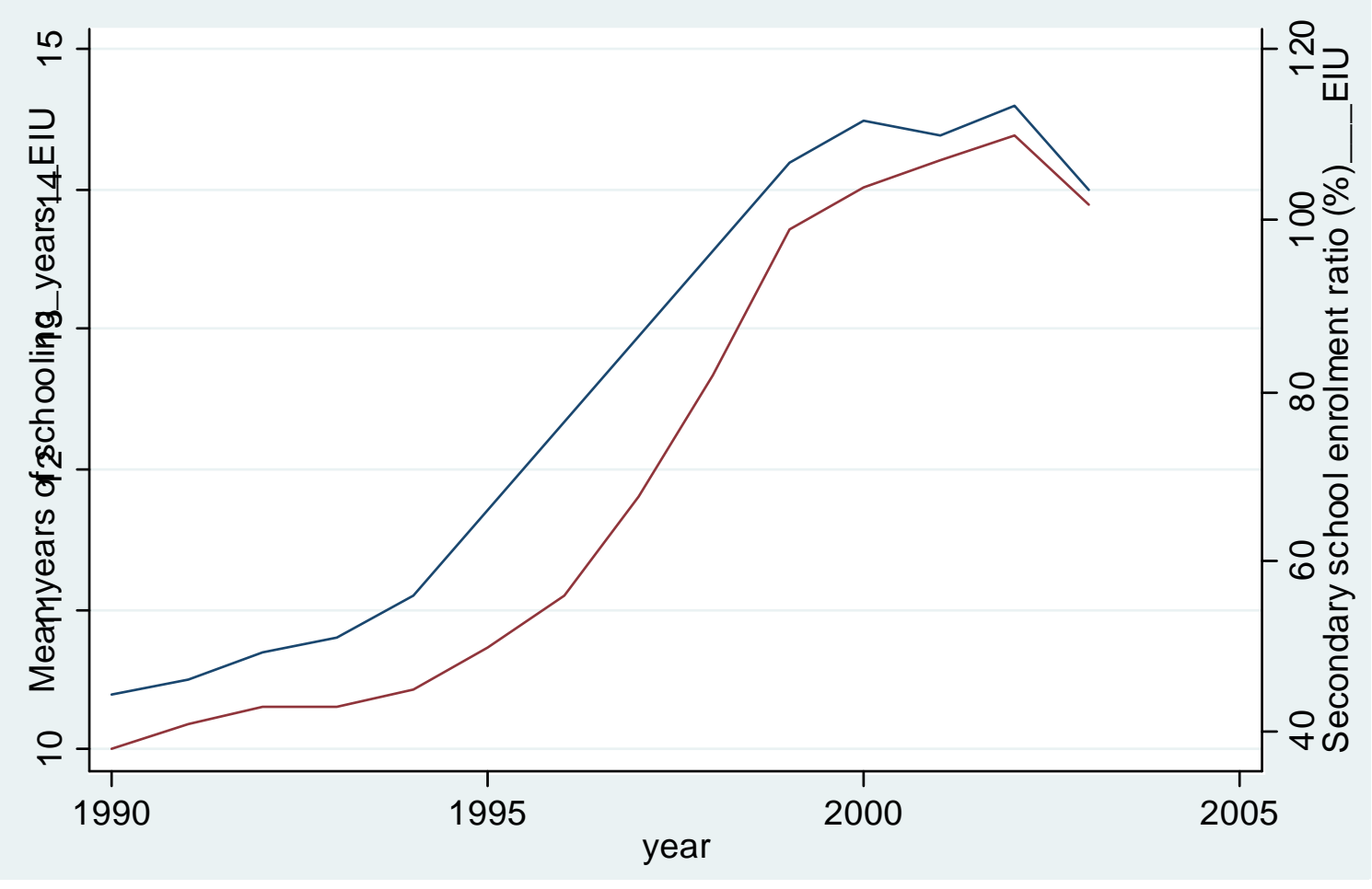

Source: Economist Intelligence Unit 
Figure 11. Maximum rate of growth in any 20 year period after 1960 and final date of that period.

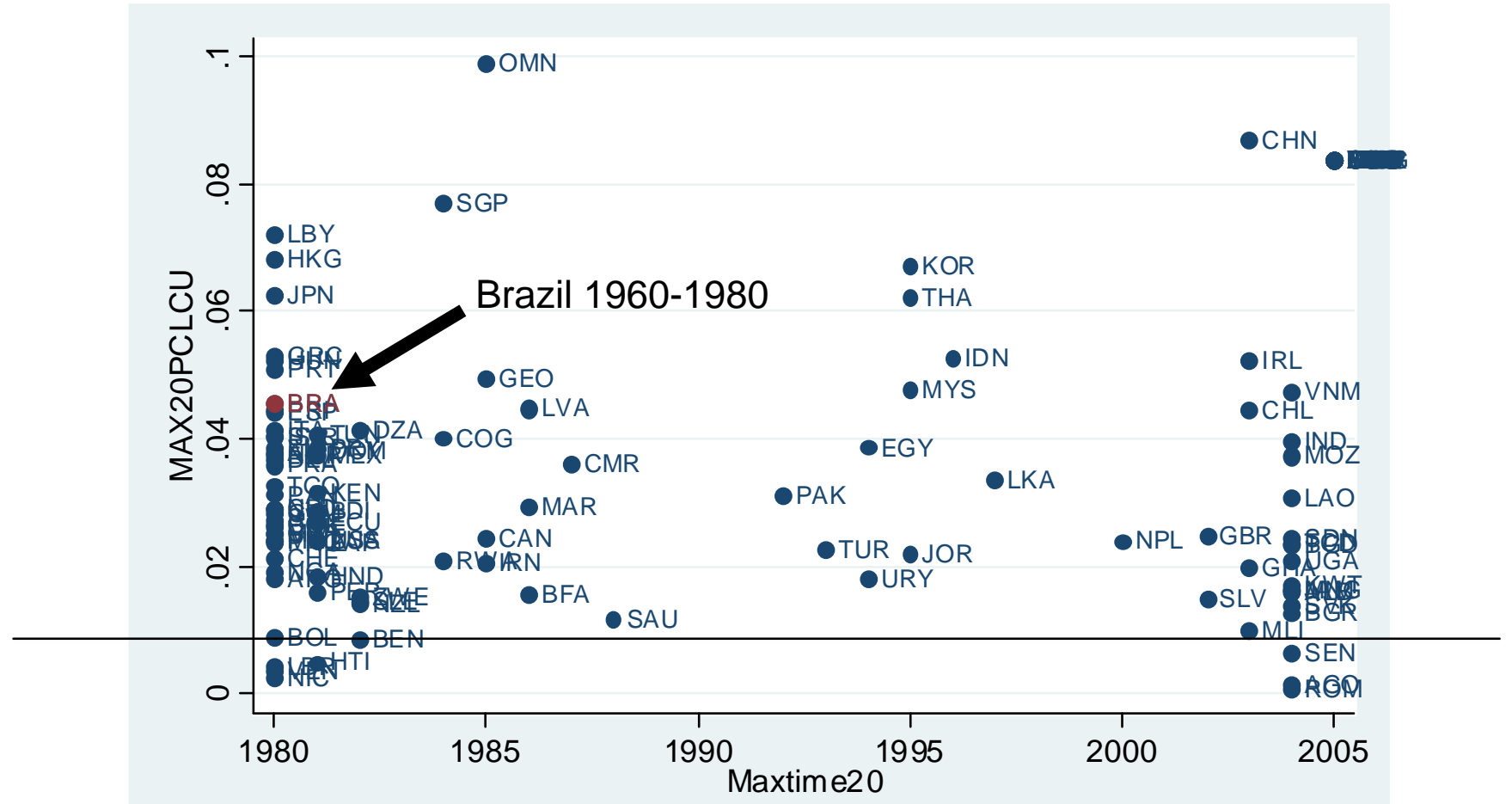

Note: the black line indicates Brazil's average rate of per capita growth in Brazil in 19872007

Source: World Development Indicators

Figure 12. Export sophistication and GDP per capita (2005)

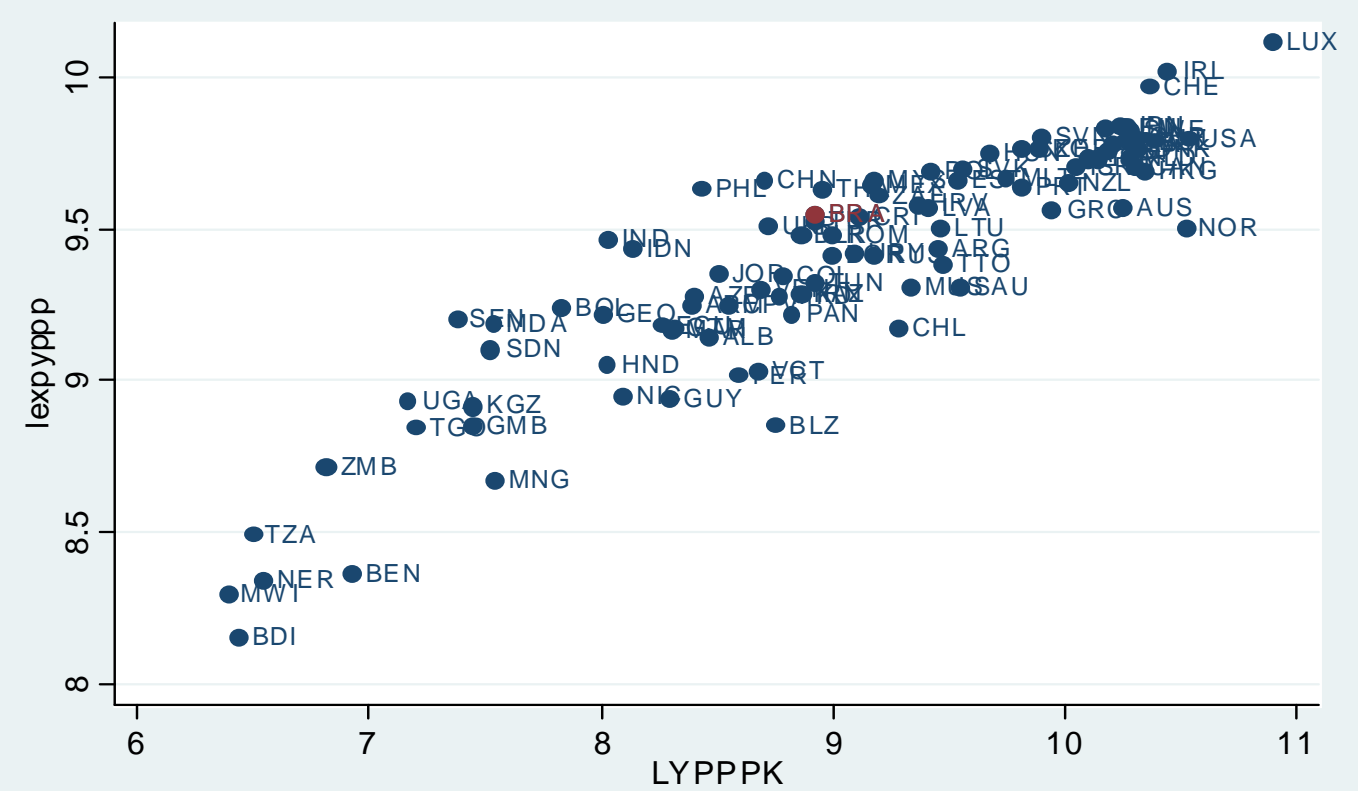

Source: calculations by Hausmann and Klinger (2007) based on COMTRADE data an WDI 
Figure 13. Initial export sophistication (1990) and subsequent growth (1990-2005)

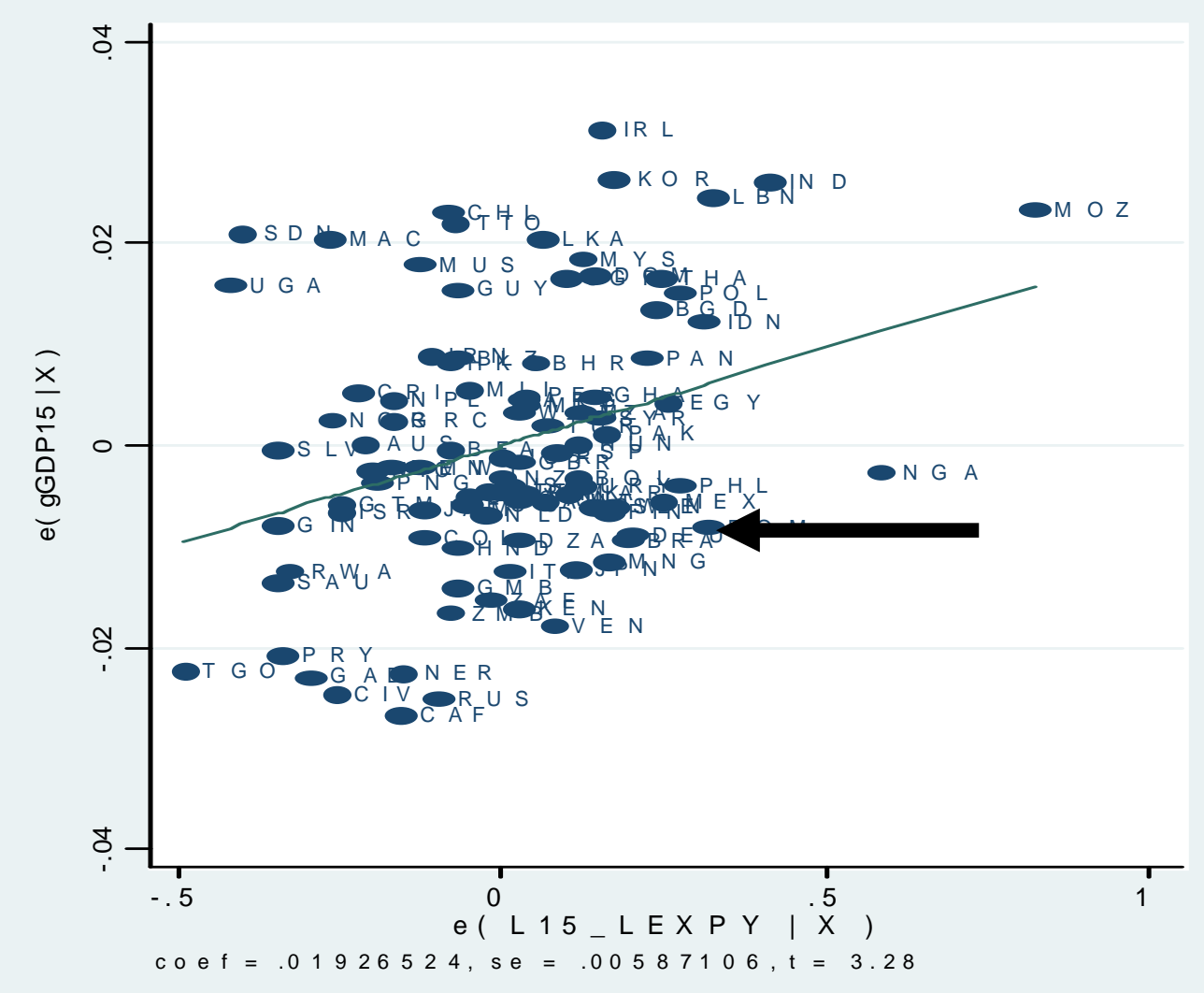

Figure 14. Open Forest and GDP per capita (2005)

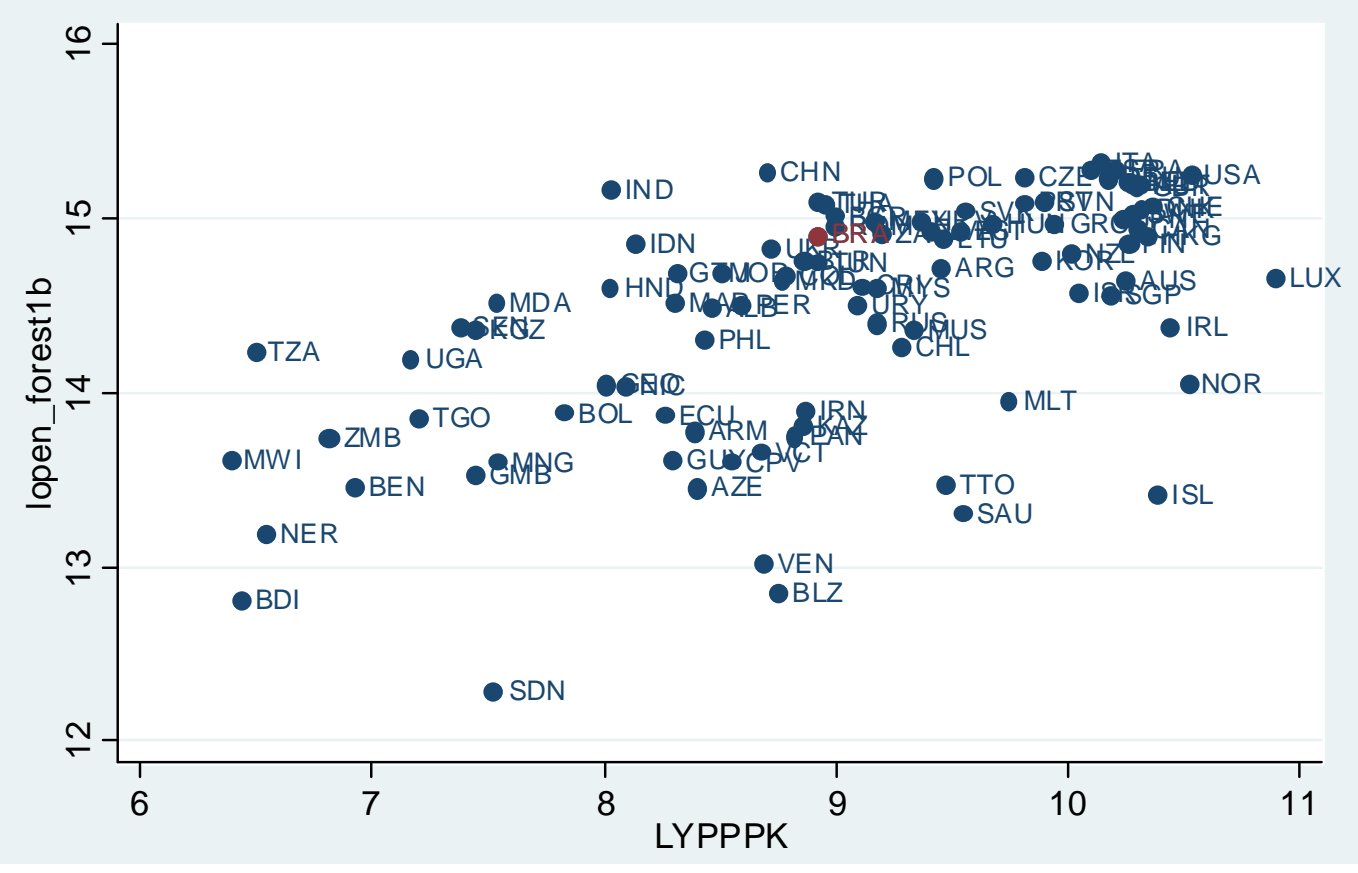


Figure 15. How much water can the barrel hold?
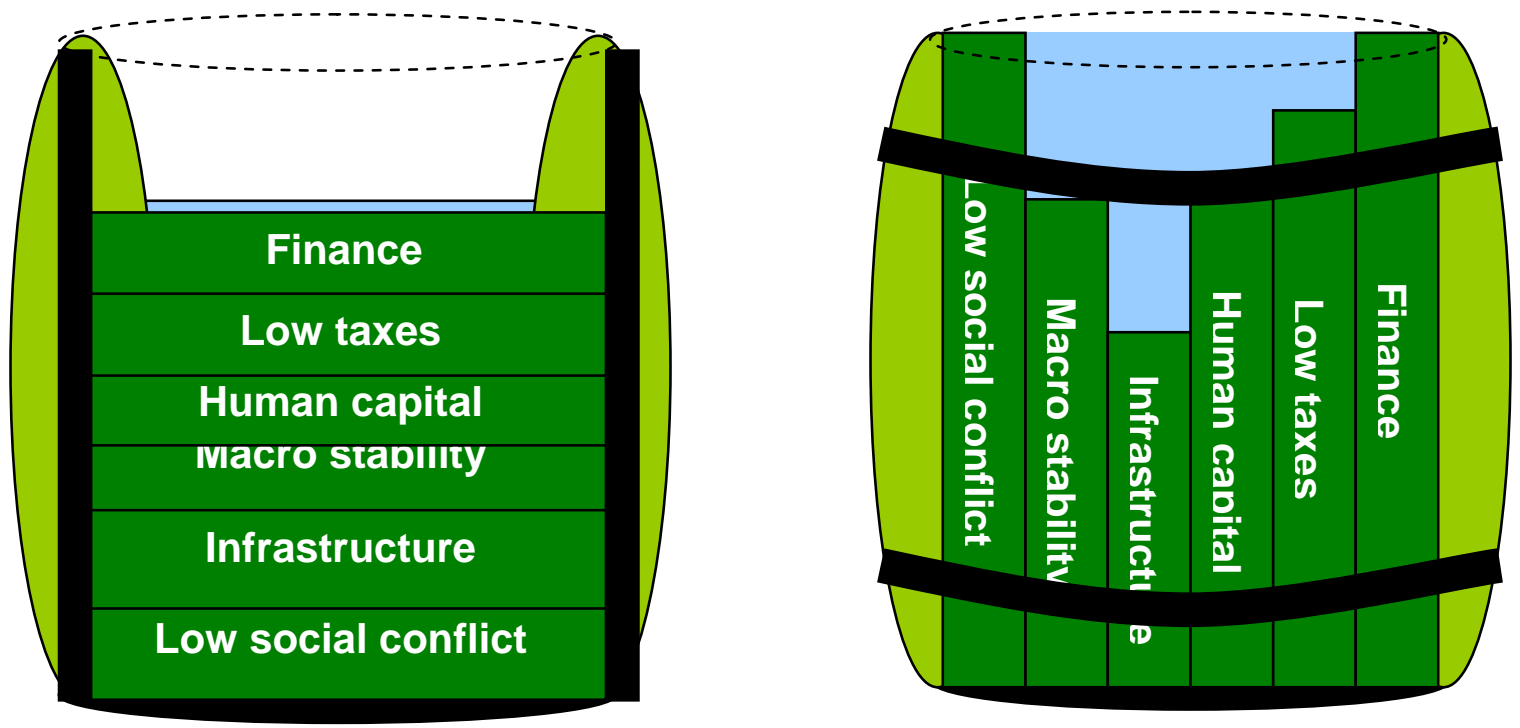

Figure 16. The Hausmann, Rodrik and Velasco (2005) decision tree

Problem: Low levels of private investment and entrepreneurship



Low return to economic activity

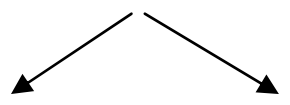

Low social returns

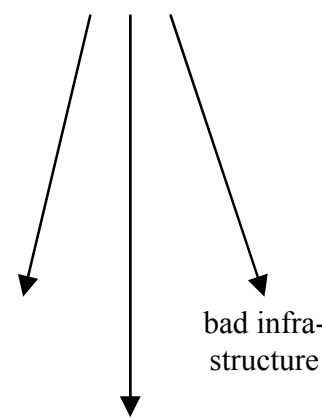

low

human

capital
Low appropriability

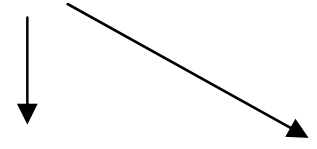

government failures

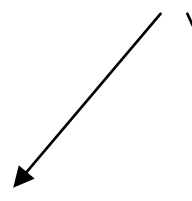

micro risks: property rights, corruption, taxes



High cost of finance

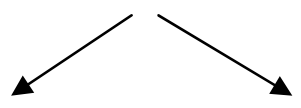

Low domestic bad local finance savings + bad international finance

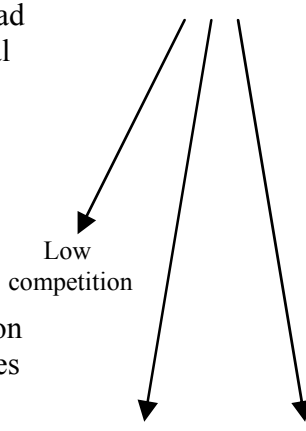

High risk High cost market failures

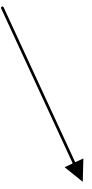

macro risks:

financial, monetary, fiscal instability



externalities: 
Figure 17. Brazilian GDP per capita relative to the United States
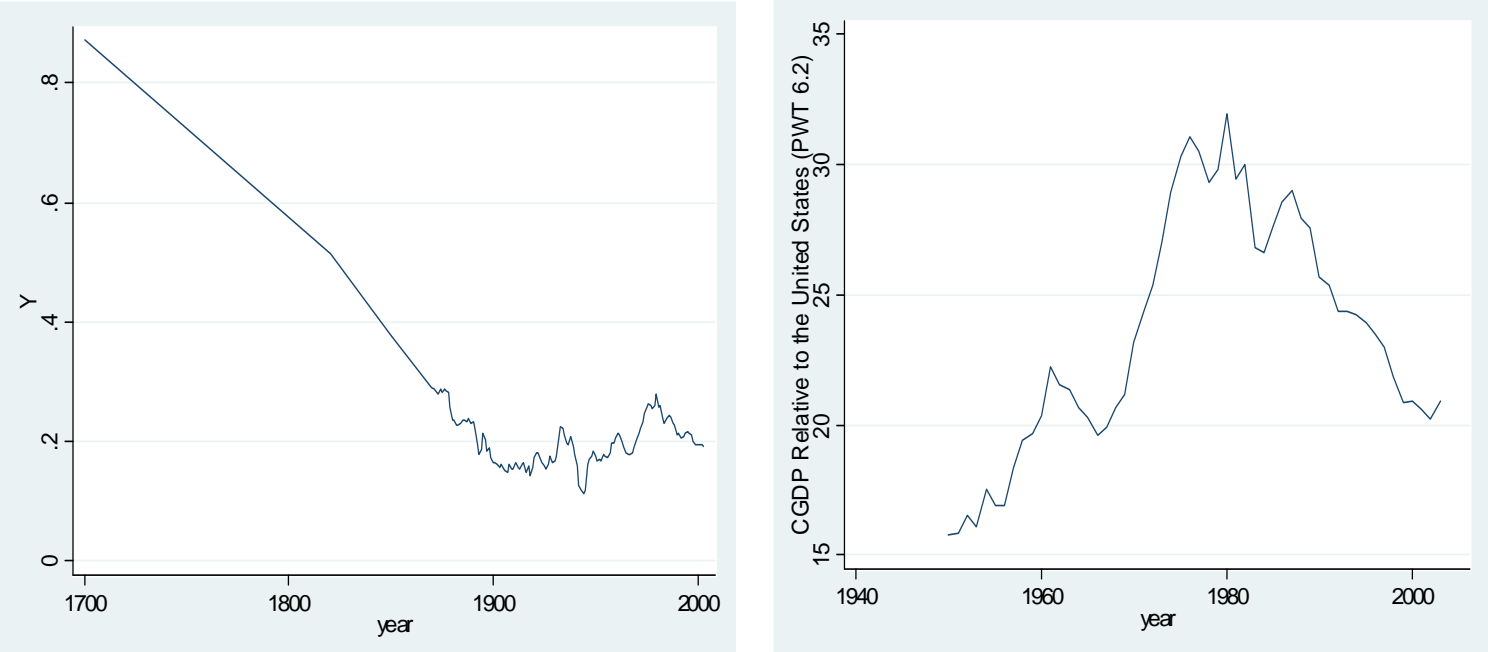

Source: Maddison for 1700-2000 and Penn World Tables 6.2 for 1945-2001

Figure 18. Average real ex-post bank lending rates 2005-2007 vs. log of GDP per capita

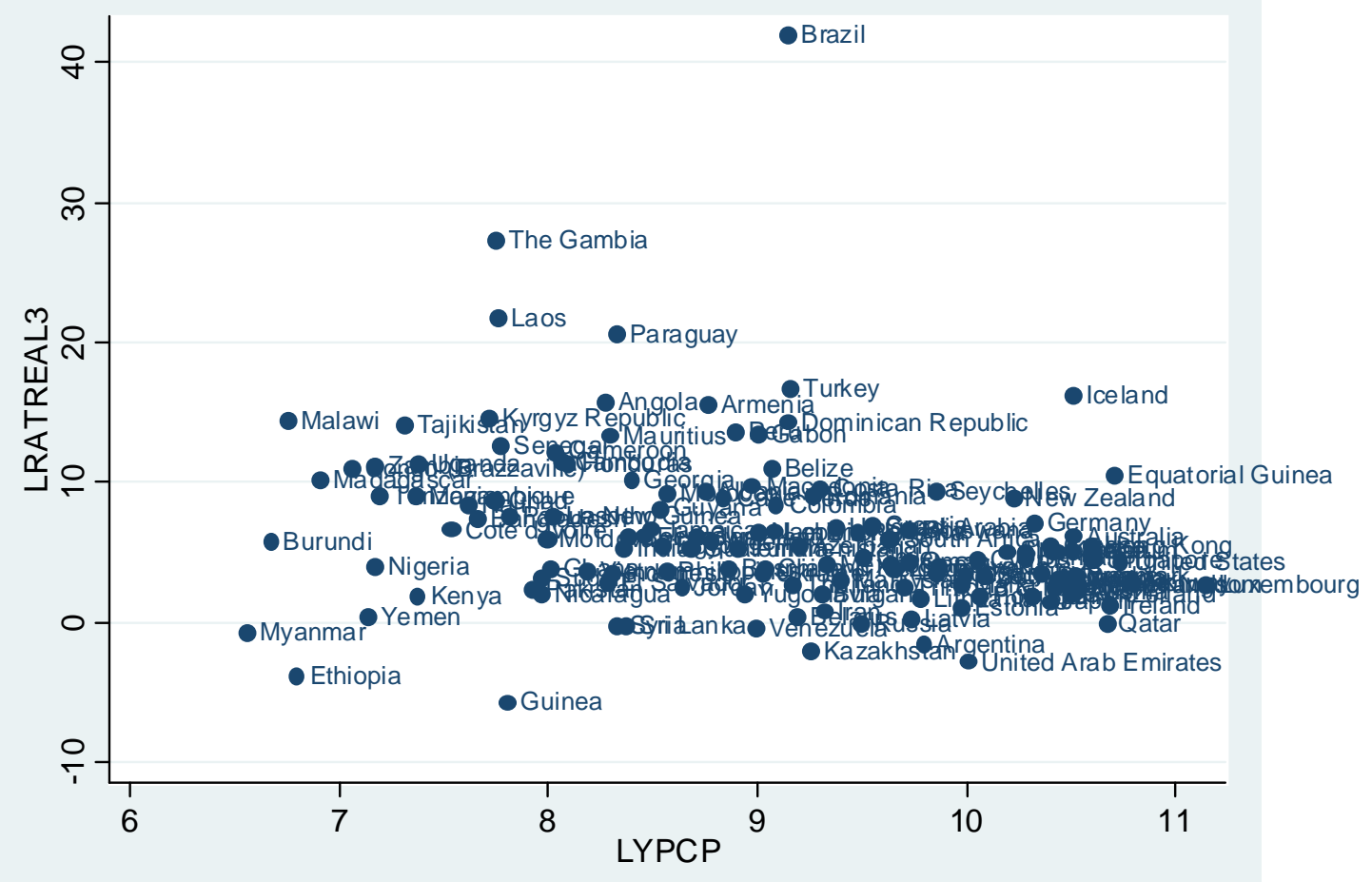

Source: Economist Intelligence Unit 
Figure 19. Real interest rate and investment rate (2005-2007)

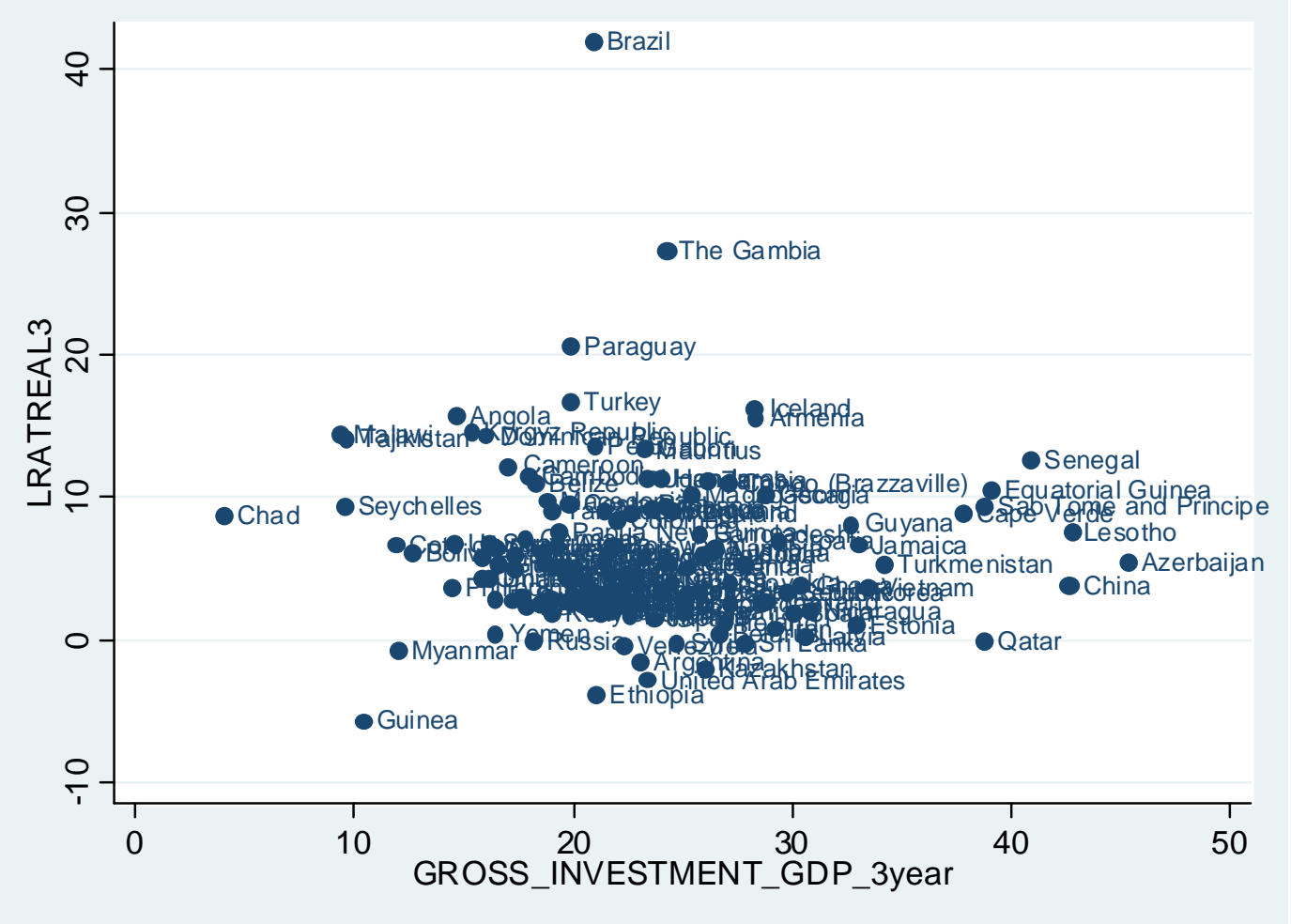

Source: Economist Intelligence Unit

Figure 20. Theoretical representation of the Brazilian investment predicament




Figure 21. Lending rate and investment ratio Brazil 2000-2007

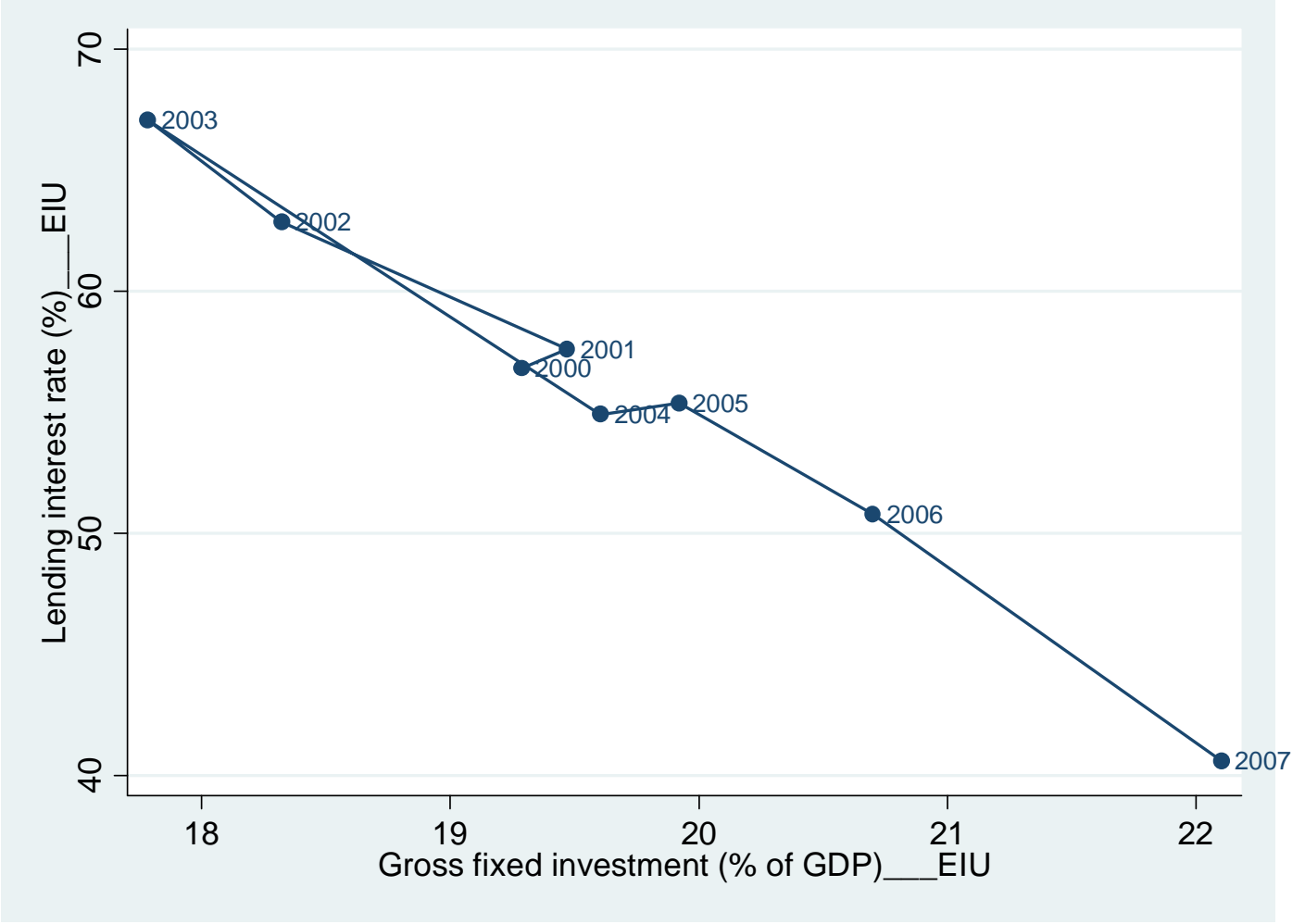

Figure 22. Percentage of companies complaining of high taxes

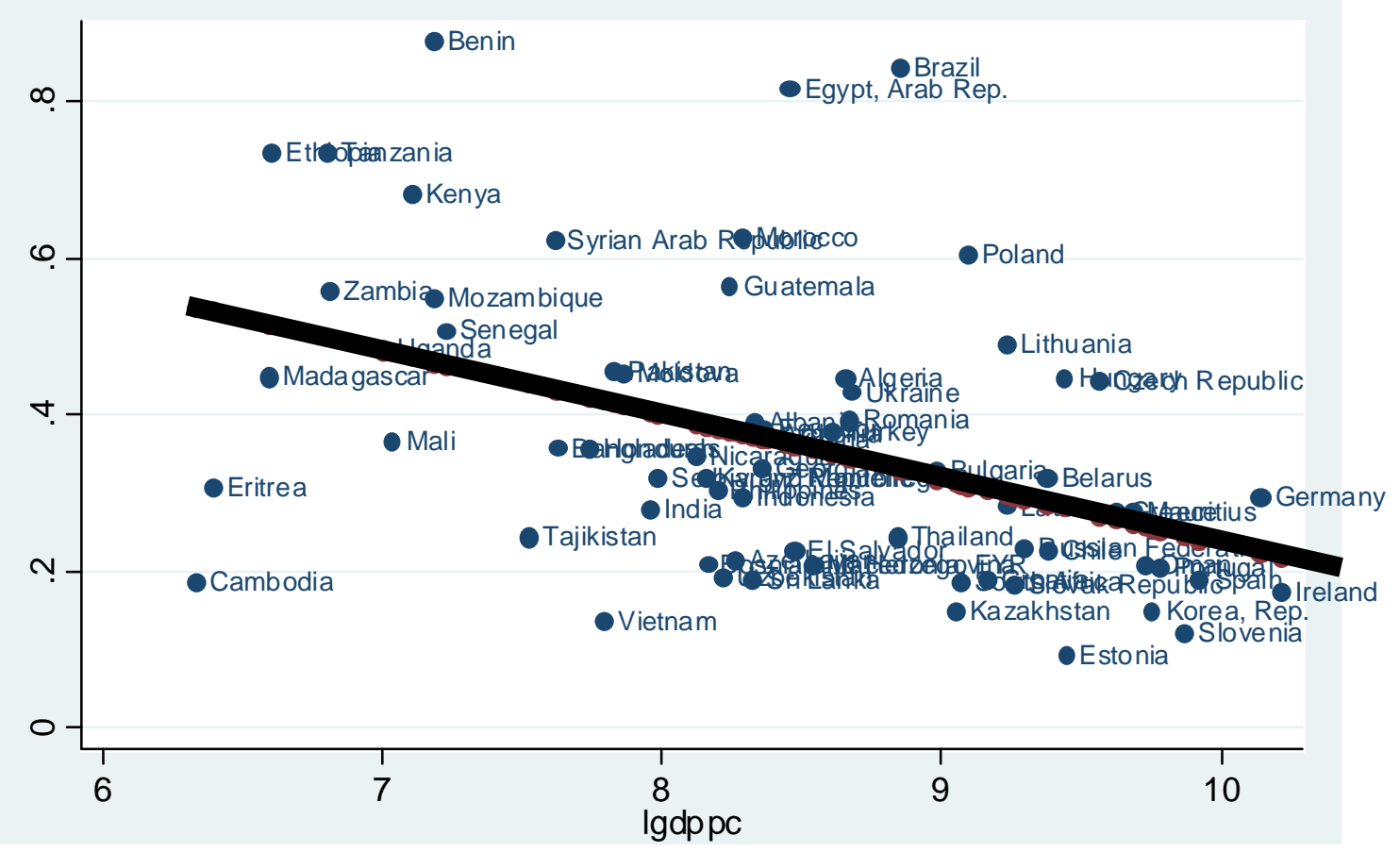

Source: World Bank Investment Climate Assessments 
Figure 23 Real ex-post average deposit rate (2005-2007)

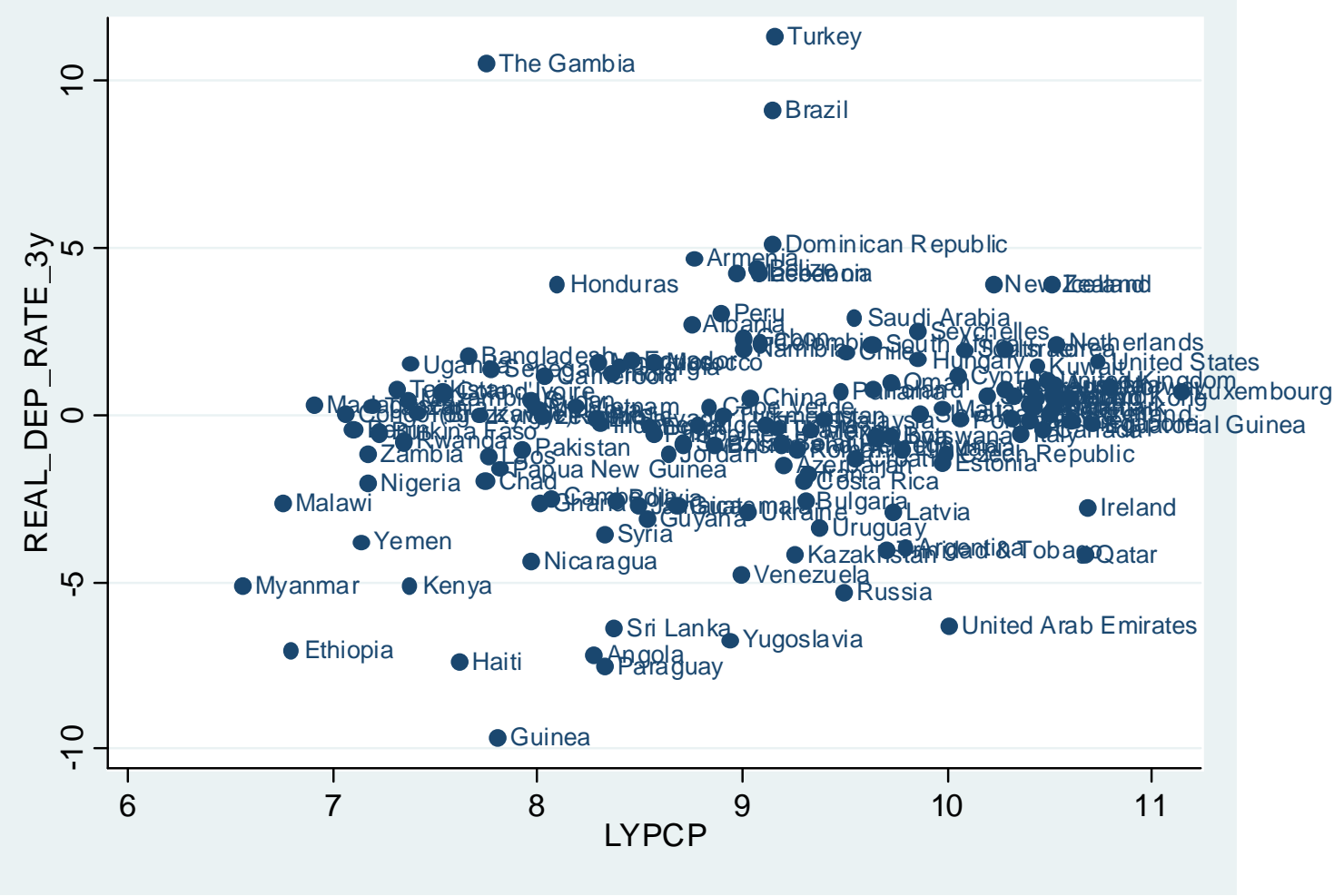

Source: Economist Intelligence Unit

Figure 24. Spread between lending and deposit rates, average 2005-2007

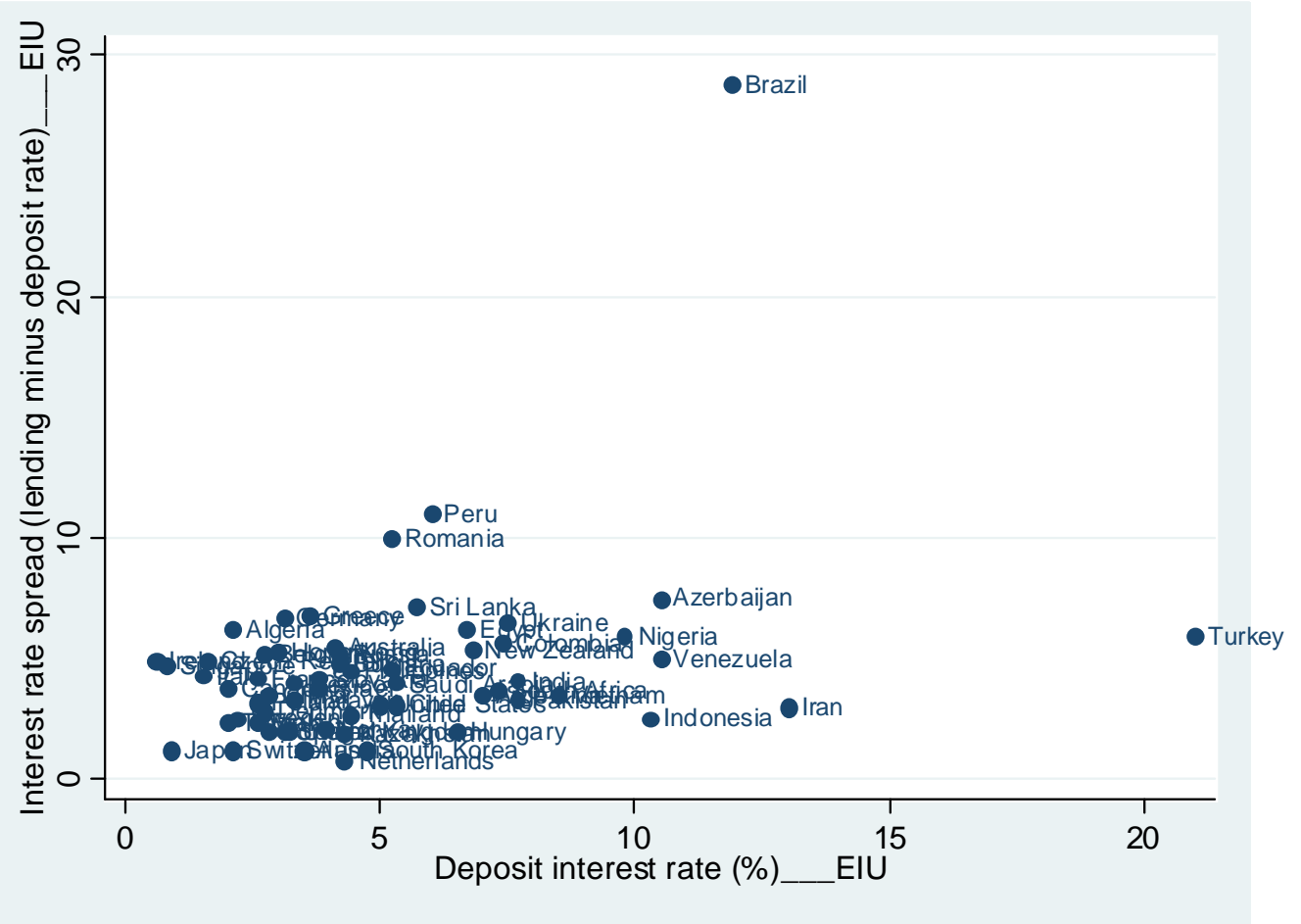

Source: Economist Intelligence Unit 
Figure 25. Brazil: Bank interest rate spread and lending rate 1997-2007

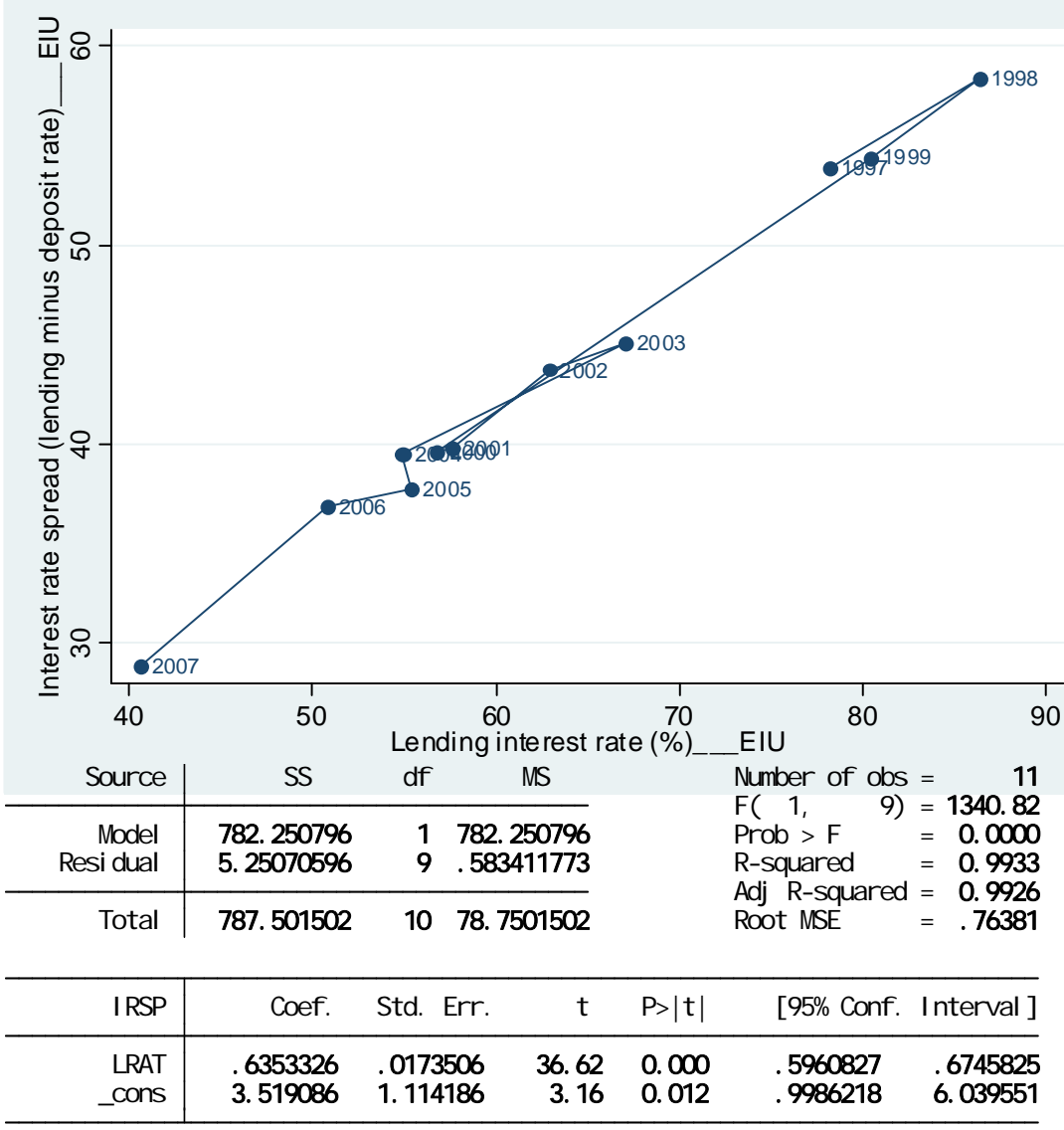

Source: Economist Intelligence Unit 
Figure 26. average years of schooling of the labor force in tradables vs. non-tradables (circa 2001)

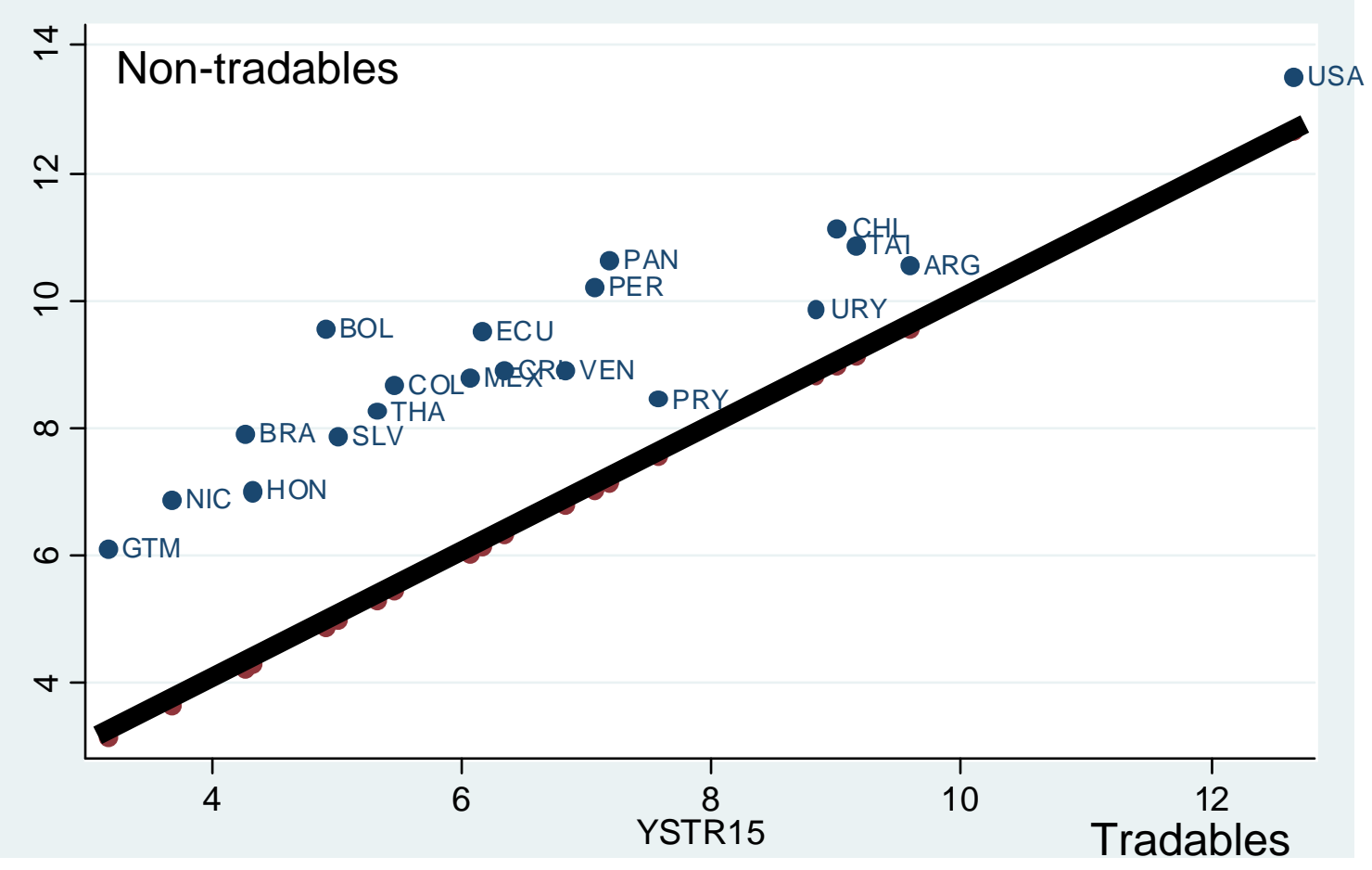

Source: Household surveys compiled by the Inter-American Development Bank

Figure 27. Percentage of university graduates in tradables and non-tradables circa 2001




Figure 28. Percentage of college graduates in non-tradables vs. manufacturing 2001

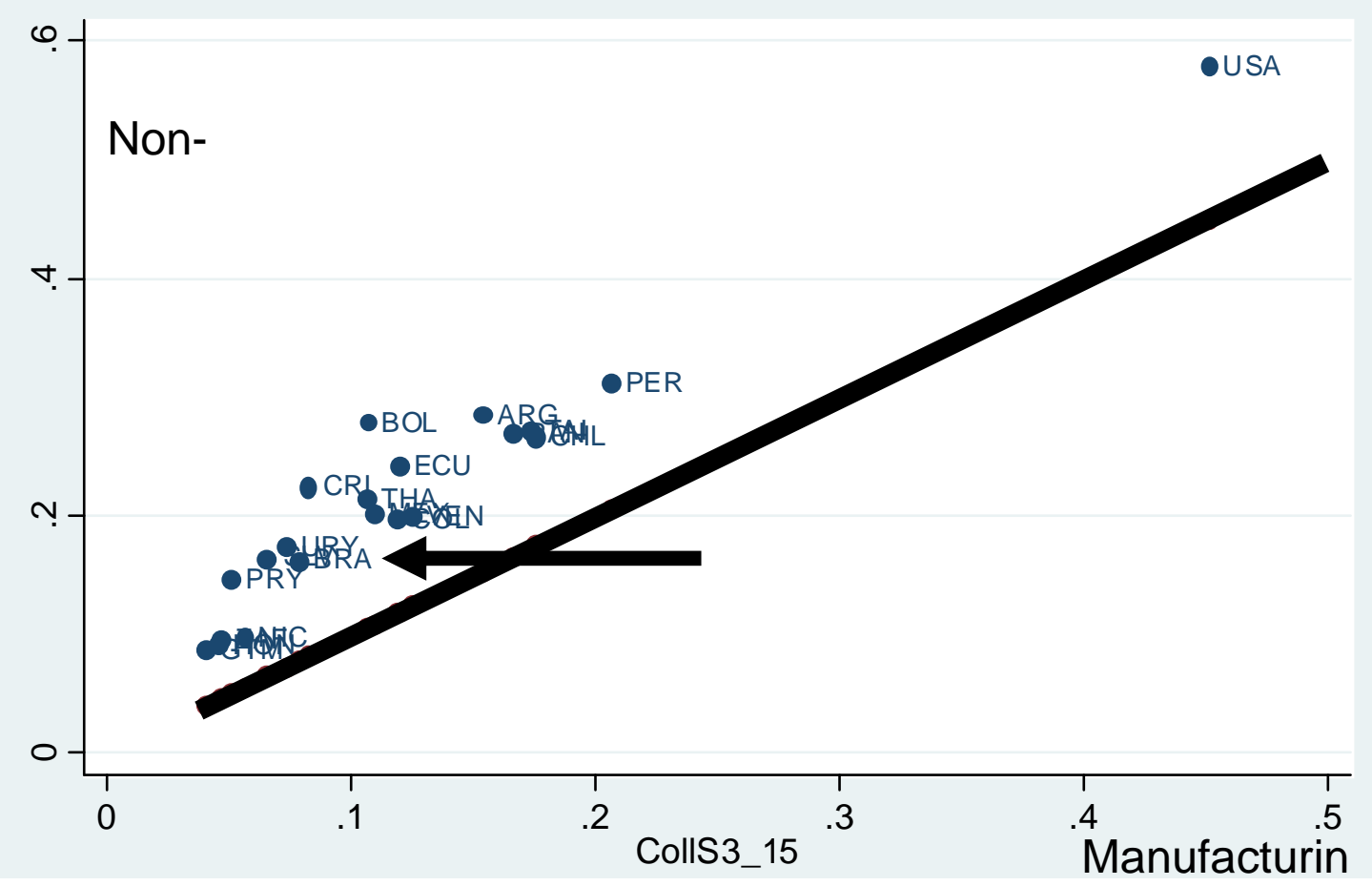

Source: Household surveys compiled by the Inter-American Development Bank

Figure 29. College wage premium and average percentage of college graduates in the labor force, 2001




Figure 30. Mincerian returns to an additional year of schooling and average years of schooling of the labor force, 2001

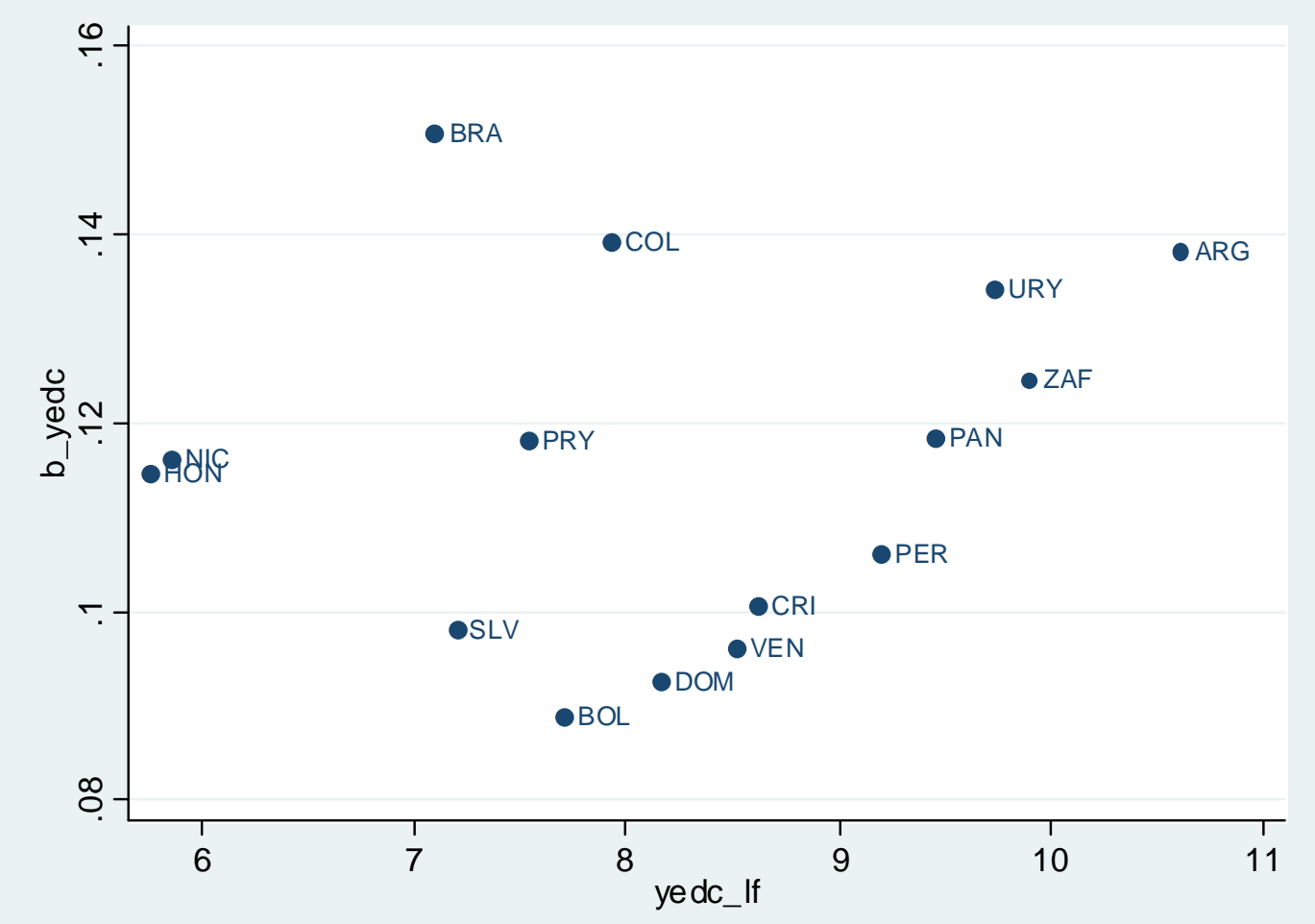

Source: Household surveys compiled by the IDB

Figure 31. Real exchange rate volatility 1997-2007 vs. log of GDP per capita

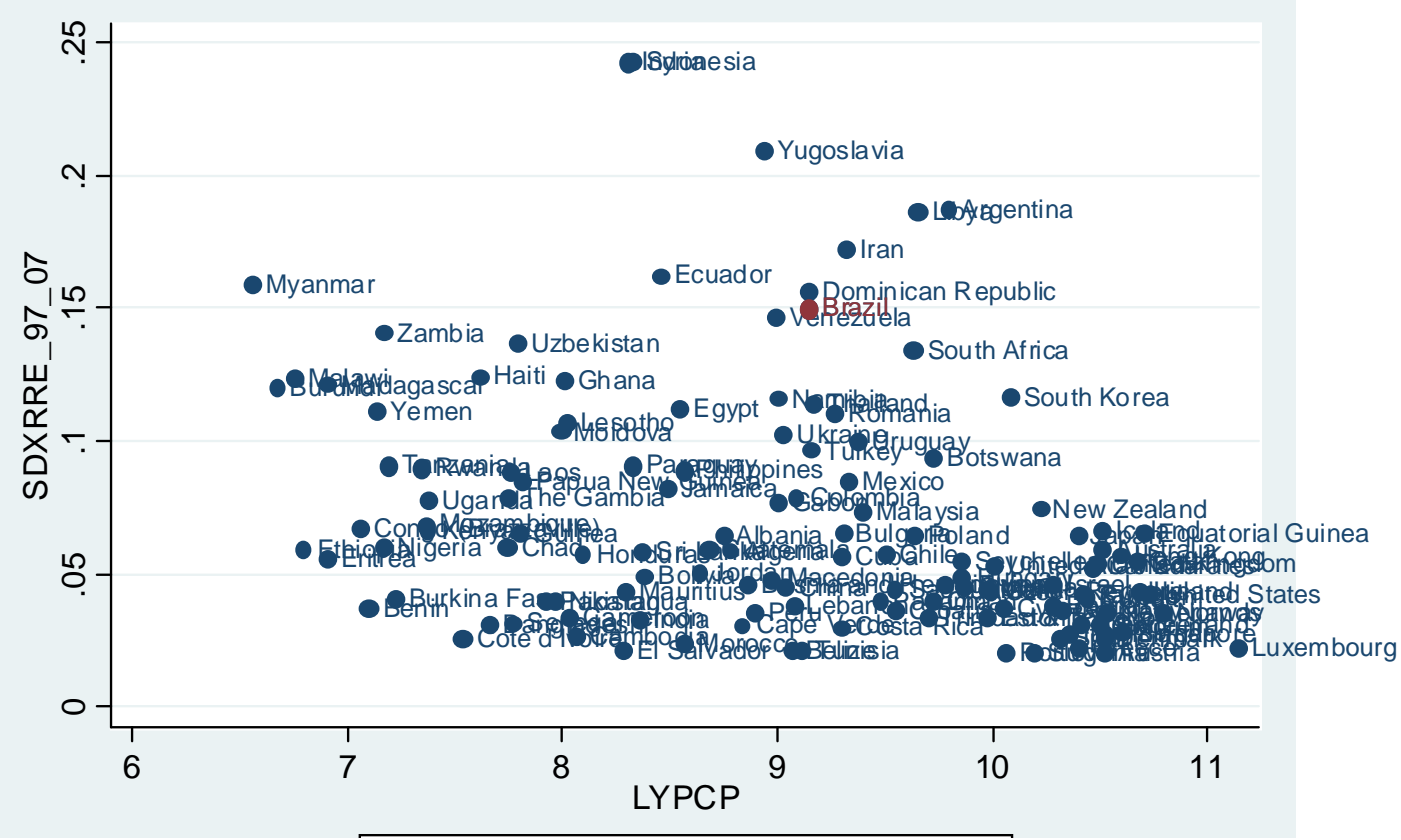

Source: Economist Intelligence Unit 
Figure 32. Public consumption (NCG) and investment (NFIS) as a share of GDP



Source: International Monetary Fund

Figure 33. General Government Revenue as a share of GDP

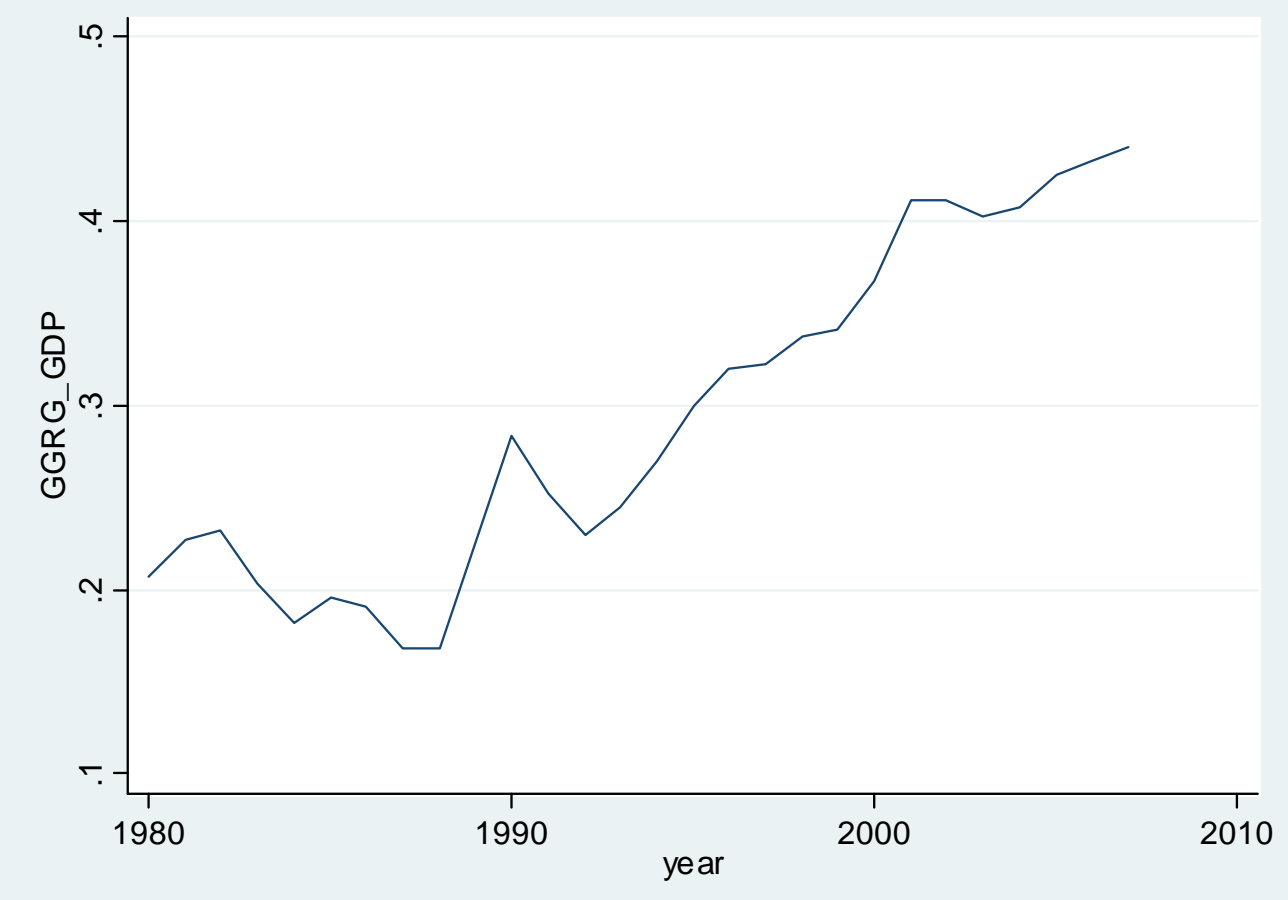

Source: International Monetary Fund 
Figure 34. General government revenue and grants as a share of GDP 2007

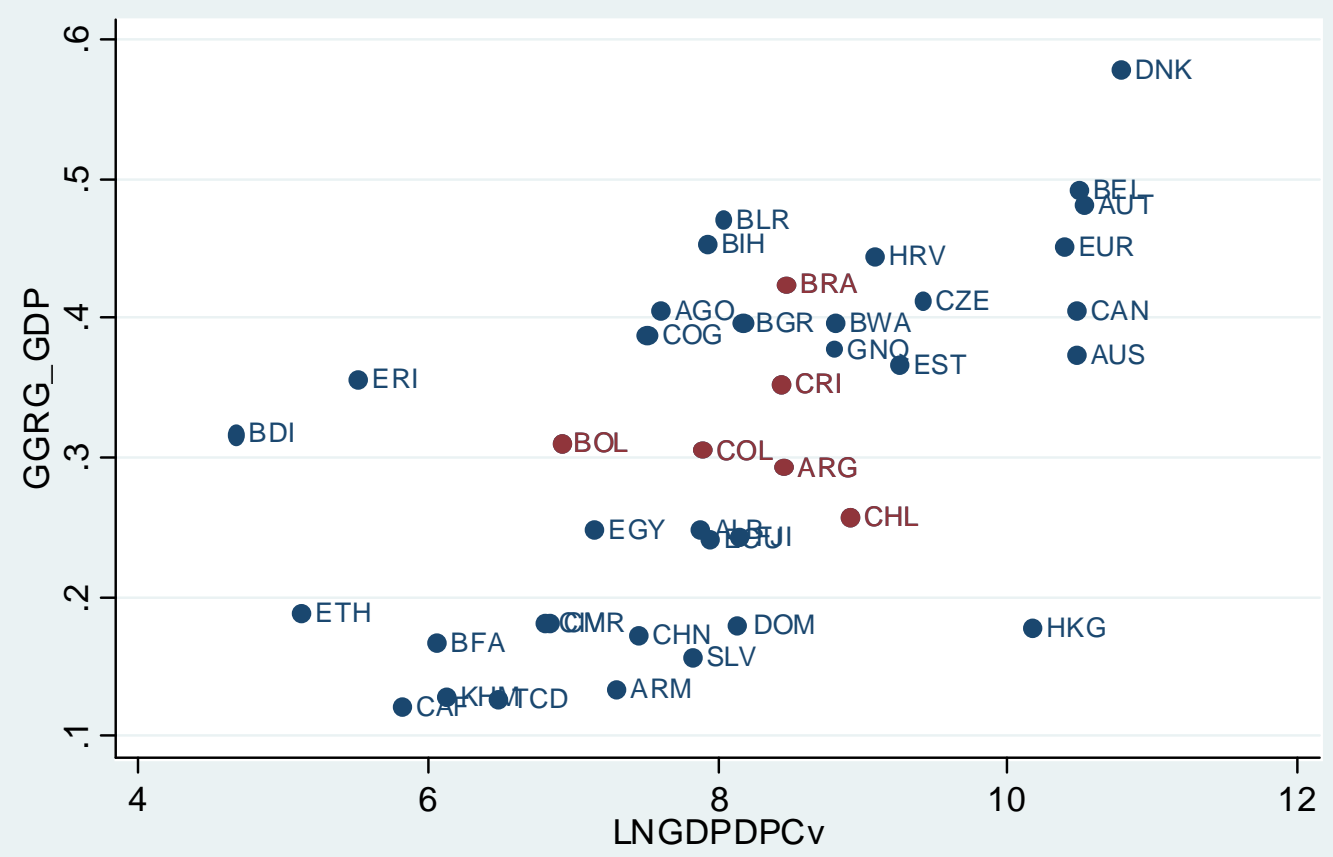

Source: International Monetary Fund

Figure 35. Public investment as a share of GDP 2007

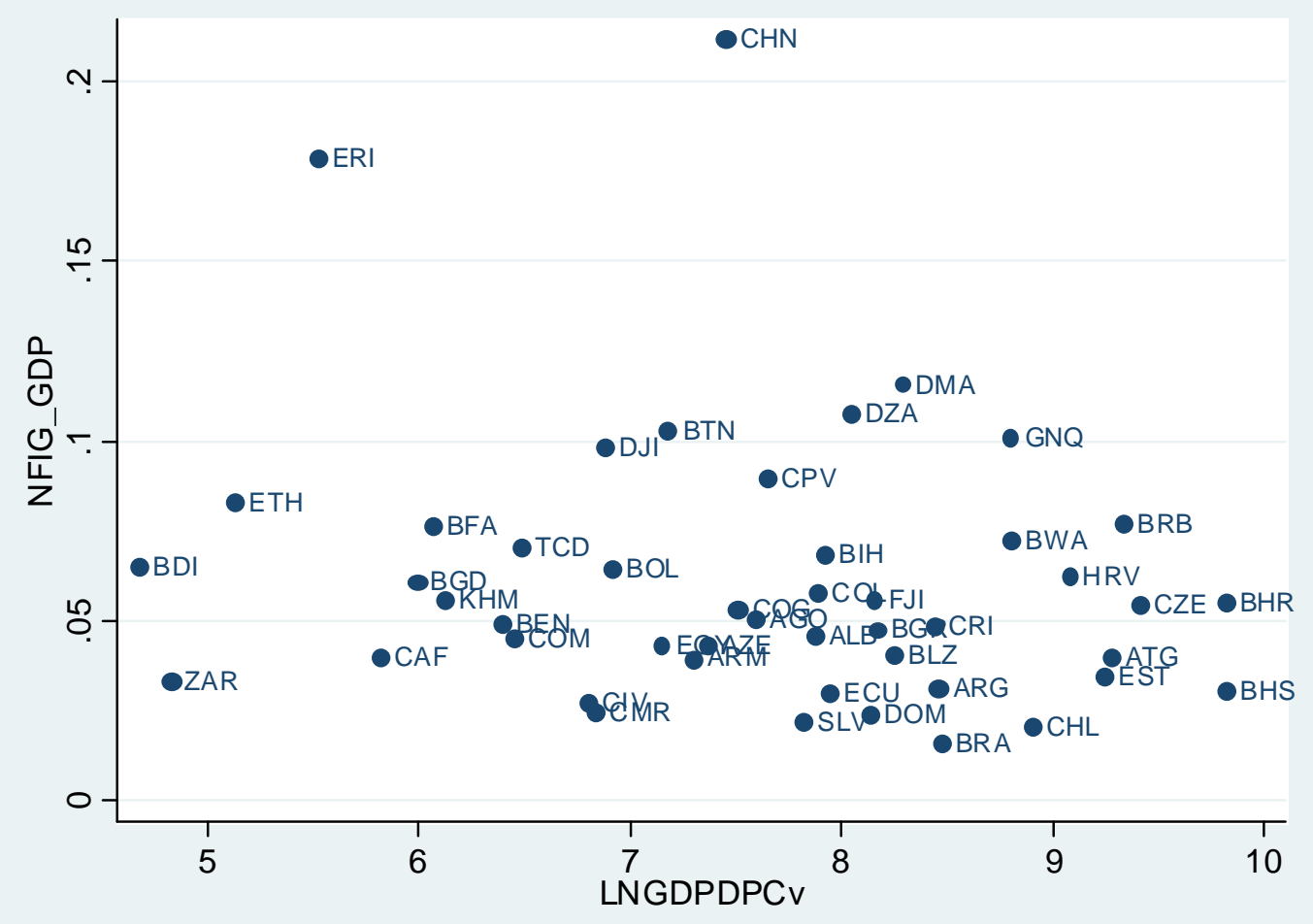

Source: International Monetary Fund 
Figure 36. Public investment and General Government deficit as a share of GDP



Source: International Monetary Fund

Figure 37.

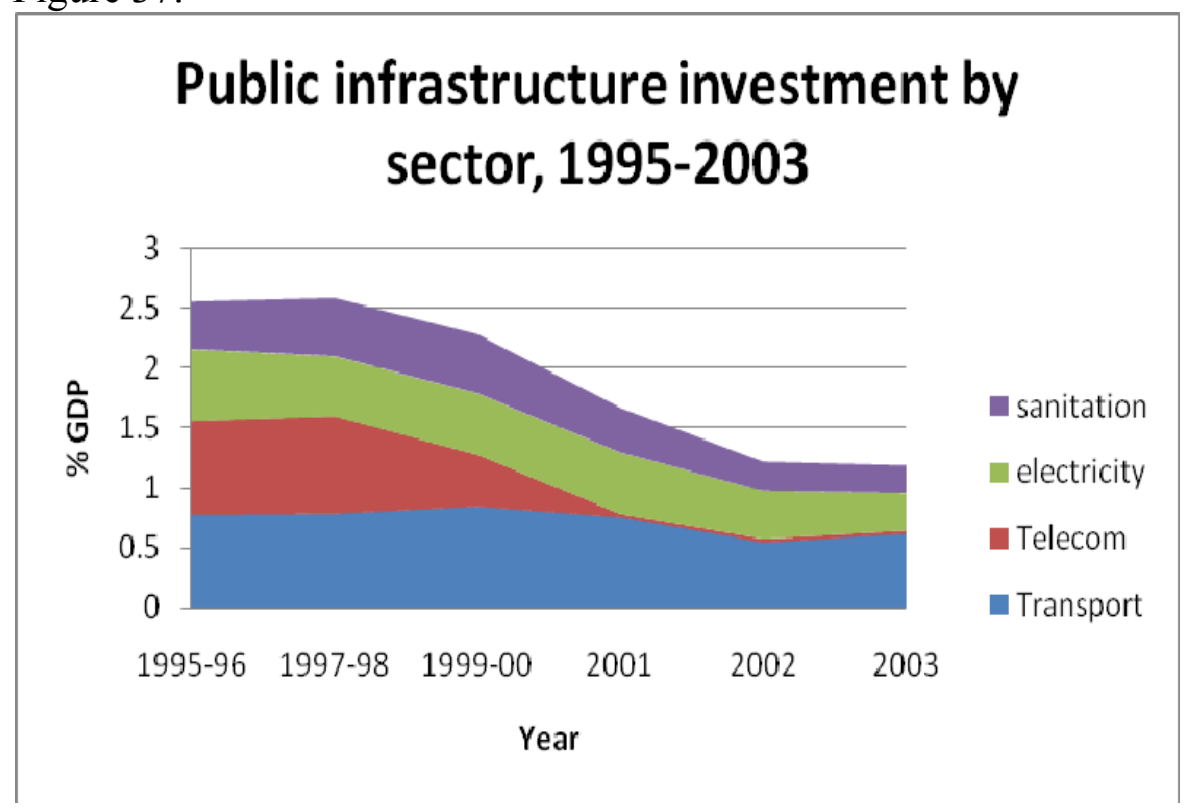

Source: World Bank (2007b) 
Figure 38. Private Investment in Infrastructure



